\title{
Understanding the Polar Character Trend in a Series of Diels-Alder Reactions Using Molecular Quantum Similarity and Chemical Reactivity Descriptors
}

\author{
Alejandro Morales-Bayuelo ${ }^{1,2}$ and Ricardo Vivas-Reyes ${ }^{2}$ \\ ${ }^{1}$ Departamento de Ciencias Químicas, Universidad Nacional Andres Bello, República 275, 8370146 Santiago, Chile \\ ${ }^{2}$ Grupo de Química Cuántica y Teórica, Programa de Química, Facultad de Ciencias Exactas y Naturales, \\ Universidad de Cartagena, Colombia
}

Correspondence should be addressed to Alejandro Morales-Bayuelo; alejandr.morales@uandresbello.edu

Received 1 March 2014; Revised 4 April 2014; Accepted 4 April 2014; Published 7 July 2014

Academic Editor: Daniel Glossman-Mitnik

Copyright (C) 2014 A. Morales-Bayuelo and R. Vivas-Reyes. This is an open access article distributed under the Creative Commons Attribution License, which permits unrestricted use, distribution, and reproduction in any medium, provided the original work is properly cited.

\begin{abstract}
In molecular similarity there is a premise "similar molecules tend to behave similarly"; however in the actual quantum similarity field there is no clear methodology to describe the similarity in chemical reactivity, and with this end an analysis of charge-transfer (CT) processes in a series of Diels-Alder (DA) reactions between cyclopentadiene (Cp) and cyano substitutions on ethylene has been studied. The CT analysis is performed in the reagent assuming a grand canonical ensemble and the considerations for an electrophilic system using B3LYP/6-31G $(d)$ and M06-2X/6-311 $+G(d, p)$ methods. An analysis for CT was performed in agreement with the experimental results with a good statistical correlation $\left(R^{2}=0.9118\right)$ relating the polar character to the bond force constants in DA reactions. The quantum distortion analysis on the transition states (TS) was performed using molecular quantum similarity indexes of overlap and coulomb showing good correlation $\left(R^{2}=0.8330\right)$ between the rate constants and quantum similarity indexes. In this sense, an electronic reorganization based on molecular polarization in terms of CT is proposed; therefore, new interpretations on the electronic systematization of the DA reactions are presented, taking into account that today such electronic systematization is an open problem in organic physical chemistry. Additionally, one way to quantify the similarity in chemical reactivity was shown, taking into account the dependence of the molecular alignment on properties when their position changes; in this sense a possible way to quantify the similarity of the CT in systematic form on these DA cycloadditions was shown.
\end{abstract}

\section{Introduction}

Since its discovery, the Diels-Alder (DA) reactions have become one of the most relevant reactions in synthetic organic chemistry due to their ability to create cyclic unsaturated compounds with a predictable stereochemistry and regioselectivity [1-8]. For its amazing performance and utility especially in organic chemistry its discovery was recognized by the Nobel Prize in Chemistry. DA reactions have been mechanistically classified as pericyclic reactions $[9,10]$. The viability of these chemical processes has been related to the well-known Woodward-Hoffmann rules [11, 12]. But some mechanistic aspects of DA reactions still remain which have not been explicated in appropriate way and therefore its electronic systematization is an open problem in organic chemistry until today and can be considered as a bottleneck in DA reactions.

Analysis based on the orbital symmetry, regioselectivity, and stereoselectivity in DA reactions confirms that many characteristics of DA reactions are modulated essentially by charge transfer $(\mathrm{CT})$ processes between the diene and dienophile; for this reason it is studied in this work. In this sense, CT appears as a key factor that allows us rationalize the nature of the mechanism in terms of the transition state (TS) and the activation energy associated with the process in DA reactions [1-12]. From the CT point of view, the DA reactions are classified into the following types: (a) the nonpolar DA reactions with low $\mathrm{CT}$ in the TS, (b) the polar DA reactions 
with high CT in the TS) with a zwitterionic character, and finally (c) the ionic DA reactions where the charge separation is preserved along the reaction path [1-12].

Since the implementation of DA reactions in current organic chemistry an enormous amount of experimental and theoretical work has been devoted to the study of the mechanism and selectivity of these DA cycloadditions. The reactivity and selectivity of these processes have been treated principally within the frontier molecular orbital (FMO) approximations [21-26], transition state theory (TST) [27, 28 ], and more recently using the reactivity descriptors defined in density functional theory (DFT) [1-8, 29-50].

One of the fields in quantum chemistry for feasibility study through the TSs in the DA reactions is the molecular quantum similarity (MQS) presenting possible ways of electronic systematization [51-78]. In this sense, we present a combined approach of MQS and chemical reactivity descriptors supported in DFT [79-84] to study the electronic reorganization in terms of the formation of the zwitterionic character and their CT analysis along the series of reactions shown in Figure 1 and Table 1. In the supplementary information (SI) is shows the structural geometries.

The electronic reorganization for these DA reactions has been studied widely by Domingo et al. and coworkers [1517], and they have postulated an electronic reorganization characterized by nucleophilic attack centers towards electrophilic centers to study the synchronicity in the bond formation and also have studied the pseudodiradical character to these organic systems $[85,86]$. However, other reactivity parameters, such as the polar character, have been little studied; for this reason, this study seeks to propose an electronic reorganization that can be able to explain the polar character in terms of CT and the subsequent formation of the zwitterionic character along the reaction paths in systematic form.

The reaction rate constants analyzed in this contribution are shown in Table 1 . These DA reactions have served as the most dramatic examples of pure electronic effects on rates that are not complicated by significant steric effects. Large fluctuations have been observed in terms of reaction rates; as an example the reaction involving $\mathrm{Cp}+2 \mathrm{CN}$ its rate is estimated in the order of $10^{4}$, while the $2 \mathrm{cCN}$ drops dramatically to 91 . Another example of this drastic change can be seen in the $\mathrm{Cp}+4 \mathrm{CN}$ reaction which has a reaction rate estimated in the order of $10^{7}$, while the reference reaction $(\mathrm{Cp}+\mathrm{Et})$ is estimated in the order of $10^{-5}$, taking into account that these experimental values have a factor of $10^{5} k\left(\mathrm{M}^{-1} \mathrm{~S}^{-1}\right)$. In order to determine a possible electronic rationalization of these large fluctuations, in this study direct considerations on the electronic density in terms of reactivity descriptors and MQS are used.

Recently, the chemical reactivity and quantum similarity relationship in order to understand the electronic reorganization and molecular polarization using quantum similarity descriptors [87-91] has been studied. As the similarities in chemical reactivity depend on molecular properties and due to the crucial role of the electronic density in MQS, it is quite natural that a close relation exists between chemical reactivity and quantum similarity (QS) [92-103]. Consequently, this study analyzes the chemical reactivity and MQS relationship to postulate a possible way of electronic systematization on the DA reactions of Table 1 in DFT framework. Additionally, using similarity relations Woodward-Hoffmann postulated the well-known rules through the FMO [11, 12]; therefore, in this study we used the MQS field to postulate a possible explanation of the polar character consistent with the experimental results and describe the similarity on the chemical reactivity of these cycloadditions in the DFT context.

The structure of this paper will be as follows. The theory and computational details are described in Sections 2 and 3, respectively, and the results and discussions are developed in Section 4, and finally in Section 5 the most important conclusions are discussed.

\section{Theory}

2.1. Global and Local Reactivity Descriptors. The global reactivity descriptors have a very well-known history in quantum chemistry that has been justified from theoretical point of view in the DFT framework [79-84] such as chemical potential $(\mu)$ [79-84], hardness $(\eta)[104]$, and softness $(S)[105,106]$, and these global descriptors are calculated using Koopmans theorem "i.e., the energies of the higher occupied molecular orbital (HOMO) and the lowest unoccupied molecular orbital (LUMO) are equal to the negative of first ionization potential and of the electronic affinity, resp." and three-point differential statistical as

$$
\begin{gathered}
\mu \approx \frac{\mathrm{IP}+\mathrm{EA}}{2}=\frac{\varepsilon_{H}+\varepsilon_{L}}{2}, \\
\eta \approx \varepsilon_{L}-\varepsilon_{H} \\
S=\frac{1}{\eta} .
\end{gathered}
$$

The chemical potential (see (1)) can be interpreted as a measure of the tendency of an electron to escape from the electronic cloud and the hardness $(\eta)$ is a measure of the resistance imposed by the system to the changes in the electronic distribution. In these equations $\left(\varepsilon_{L}\right)$ and $\left(\varepsilon_{H}\right)$ represent the energies of the HOMO and LUMO, respectively.

Using (1) and (2) the electrophilicity ( $\omega)$ index [107] is defined as

$$
\omega \approx \frac{\mu^{2}}{2 \eta},
$$

where $(\omega)$ is other global property and represents the stabilization energy of the system when it is saturated by electrons from the external environment; in this sense the electrophilicity is dependent on the saturation condition $[79-82,108]$ determined by the chemical potential $(\mu)$ and hardness $(\eta)$ and obtained as

$$
\Delta N_{\max } \approx-\frac{\mu}{\eta}
$$


TABLE 1: Reaction rate constant $(K)$ with the factor $10^{5} k\left[\mathrm{M}^{-1} \mathrm{~S}^{-1}\right]$ and activation energy $(\mathrm{kcal} / \mathrm{moL})$ for the DA reactions of cyclopentadiene $(\mathrm{Cp})$ as nucleophile with dienophiles at $20^{\circ} \mathrm{C}$; see [13] reported by Sauer et al. [14] and also see [15-20].

\begin{tabular}{|c|c|c|c|c|c|c|c|}
\hline Reactions (R-V) & $\mathrm{X}^{1}$ & $\mathrm{X}^{2}$ & $\mathrm{X}^{3}$ & $\mathrm{X}^{4}$ & Dienophile & TS-Y & $K\left(10^{5} k\left[\mathrm{M}^{-1} \mathrm{~S}^{-1}\right]\right)^{\mathrm{a}}$ \\
\hline $\mathrm{R}-1$ & $\mathrm{H}$ & $\mathrm{H}$ & $\mathrm{H}$ & $\mathrm{H}$ & $\mathrm{Et}^{\mathrm{b}}$ & TS-Et & $\sim 10^{-5}$ \\
\hline $\mathrm{R}-2$ & $\mathrm{H}$ & $\mathrm{CN}$ & $\mathrm{H}$ & $\mathrm{H}$ & $1 \mathrm{CN}$ & TS-1CN & 1.04 \\
\hline $\mathrm{R}-3$ & $\mathrm{CN}$ & $\mathrm{H}$ & $\mathrm{H}$ & $\mathrm{CN}$ & $2 \mathrm{tCN}$ & TS-2tCN & 81 \\
\hline $\mathrm{R}-4$ & $\mathrm{H}$ & $\mathrm{CN}$ & $\mathrm{H}$ & $\mathrm{CN}$ & $2 \mathrm{cCN}$ & $\mathrm{TS}-2 \mathrm{cCN}$ & 91 \\
\hline $\mathrm{R}-5$ & $\mathrm{CN}$ & $\mathrm{CN}$ & $\mathrm{H}$ & $\mathrm{H}$ & $2 \mathrm{CN}$ & TS-2CN & $4.8 \times 10^{4}$ \\
\hline R-6 & $\mathrm{CN}$ & $\mathrm{CN}$ & $\mathrm{H}$ & $\mathrm{CN}$ & $3 \mathrm{CN}$ & TS-3CN & $4.8 \times 10^{5}$ \\
\hline $\mathrm{R}-7$ & $\mathrm{CN}$ & $\mathrm{CN}$ & $\mathrm{CN}$ & $\mathrm{CN}$ & $4 \mathrm{CN}$ & TS-4CN & $4.3 \times 10^{7}$ \\
\hline
\end{tabular}

${ }^{\mathrm{a}}$ Rate constant $(K)$.

${ }^{\mathrm{b}}$ Reference reaction.

The energy reduction by CT effects is obtained by mathematical development using Taylor series for the total energy and truncated to second order as

$$
\Delta E \approx-(\omega)=-\frac{\mu^{2}}{2 \eta}
$$

The stabilization energy equation (6) can be associated with the electronic population in the microstates associated with a grand canonical ensemble and could determine the relative electrons concentration in the total electron density. The descriptors displayed in (1)-(4) depend on $(N)$ and $(\nu(r))$ and they provide information on the reactivity and stability of a chemical system [79-82]. Local properties are obtained taking into account the energy variation with respect to the external potential, and this variation depends on the position $(r)$ and can be defined as selectivity indexes; within these we have the Fukui functions [18-20, 79-82, 109-111] which explain the selectivity of a region in a molecule and are defined mathematically as

$$
\langle f(\vec{r})\rangle \approx\left(\frac{\delta \mu}{\delta \nu(\vec{r})}\right)_{N}=\left(\frac{\partial \rho(\vec{r})}{\partial N}\right)_{\nu(\vec{r})}=\left(\frac{\partial^{2} E}{\partial N \partial v(\vec{r})}\right) .
$$

The Fukui function is interpreted as the chemical potential change by external perturbation or the variation in the electronic density when the electrons number changes. The Fukui function $\left\langle f^{+}(r)\right\rangle$ using the Yang and Mortier condensed approach is calculated, the Mulliken charge in the atom $(k)$ is labeled as $q_{k}$ for the systems with $(N),(N+1)$, and $(N-1)$ electrons, respectively, and calculated at the same geometry [109-112]:

$$
\begin{aligned}
& \left\langle f_{k}^{+}(\vec{r})\right\rangle \approx \int_{k}\left[\rho_{N+1}(\vec{r})-\rho(\vec{r})\right] d r=\left[q_{k}(N+1)-q_{k}(N)\right], \\
& \left\langle f_{k}^{-}(\vec{r})\right\rangle \approx \int_{k}\left[\rho_{N}(\vec{r})-\rho_{N-1}(\vec{r})\right] d r=\left[q_{k}(N)-q_{k}(N-1)\right] .
\end{aligned}
$$

With $q_{k}(N)$ denoting the electronic population of the atom $(k)$ in the system under study, these Fukui functions in the atomic orbital condensate (AOC) approximation considers only the contribution of the frontier orbitals of an atom [112]:

$$
\begin{aligned}
& \left\langle f_{k}^{+}(\vec{r})\right\rangle \approx \int_{k} \rho_{L}(\vec{r}) d \vec{r}=L_{k} q, \\
& \left\langle f_{k}^{-}(\vec{r})\right\rangle \approx \int_{k} \rho_{H}(\vec{r}) d \vec{r}=H_{k} q,
\end{aligned}
$$

with $\left(H_{k} q\right)$ and $\left(L_{k} q\right)$ representing the electronic populations on the atom $(k)$ of the LUMO and HOMO frontier orbitals, respectively.

Using chemical reactivity descriptors based on the molecular recognition, we consider each reaction of Table 1 , as cycloaddition reactions by interaction of the nucleophile common (Cp) labeled as (A) with electrophiles labeled as (B) and the corresponding cycloadducts $(\mathrm{C})$ :

$$
\mathrm{A}+\mathrm{B} \longrightarrow \mathrm{C} \text {. }
$$

Obtaining the expressions for (5) and (6),

$$
\begin{gathered}
\Delta N_{\max }=-\frac{\mu_{\mathrm{B}}-\mu_{\mathrm{A}}}{\eta_{\mathrm{B}}+\eta_{\mathrm{A}}}, \\
\Delta E_{\mathrm{AB}}=-\frac{\left(\mu_{\mathrm{B}}-\mu_{\mathrm{A}}\right)^{2}}{2\left(\eta_{\mathrm{B}}+\eta_{\mathrm{A}}\right)} .
\end{gathered}
$$

One of the important features to study in the DA reactions is the regioselectivity. The regional or local electrophilicity at the active sites of the reagents in polar DA processes may be described on mathematic models using an extension of the global electrophilicity index introduced by Maynard et al. [82]. Considering $S=1 / \eta$ and taking in account the summatory rule for $S, S=\sum_{k S_{k}^{+}} S_{k}^{+}$see [82], we have for (6)

$$
\omega=\frac{\mu^{2}}{2 \eta}=\frac{\mu^{2}}{2} S=\frac{\mu^{2}}{2} \sum_{k} S_{k}^{+}=\sum_{k} \omega_{k}
$$

Using (13) we can define a semilocal electrophilicity condensed to the atom $(k)$ as

$$
\omega_{k}=\frac{\mu^{2}}{2} S_{k}^{+}
$$


and using the local softness and Fukui function $\left(f_{k}^{+}(\vec{r})\right)$ relationship [82]

$$
S_{k}^{+}=S f_{k}^{+}(\vec{r}) ;
$$

therefore, we have for (14)

$$
\omega_{k}=\frac{\mu^{2}}{2} S_{k}^{+}=\frac{\mu^{2} S}{2} f_{k}^{+}(\vec{r})=\omega f_{k}^{+}(\vec{r}) .
$$

Using (16) with $\omega=-\Delta E$, we have

$$
\omega_{k}=\omega f_{k}^{+}(\vec{r})=\left(\frac{\left(\mu_{\mathrm{B}}-\mu_{\mathrm{A}}\right)^{2}}{2\left(\eta_{\mathrm{B}}+\eta_{\mathrm{A}}\right)}\right) f_{k}^{+}(\vec{r}) .
$$

In this sense, also we can write $\Delta N_{\max }$ in (11) in terms of the Fukui function $f_{k}^{+}(r)$ as

$$
\Delta N_{\max }(k)=\left(-\frac{\mu_{\mathrm{B}}-\mu_{\mathrm{A}}}{\eta_{\mathrm{B}}+\eta_{\mathrm{A}}}\right) f_{k}^{+}(\vec{r}) .
$$

In this study (17) and (18) as descriptors for the polar or nonpolar character in terms of local CT are used. On the other hand, as the reactions have the sense of promoting the maximum superposition of HOMO and LUMO frontier orbitals, according to Fukui et al. [109-111], the molecular alignment is crucial and critical on the chemical reactivity; therefore in this study the quantum effects on the electronic density produced by the cyano substitutions along the DA reactions using a methodology based on molecular alignment as the MQS field are examined.

2.2. Similarity Indexes. The similarity indexes were introduced by Carbó-Dorca and coworkers almost thirty years ago $[63,70-78]$; they defined the quantum similarity measure $\mathrm{Z}_{\mathrm{AB}}$ between molecules $\mathrm{A}$ and $\mathrm{B}$ with the electronic densities $\rho_{\mathrm{A}}\left(r_{1}\right)$ and $\rho_{\mathrm{B}}\left(r_{2}\right)$ based on the idea of minimizing the expression for the Euclidean distance as

$$
\begin{aligned}
D_{\mathrm{AB}}^{2}\left(\rho_{\mathrm{A}}\left(r_{1}\right), \rho_{\mathrm{B}}\left(r_{2}\right)\right) \\
=\int\left|\rho_{\mathrm{A}}\left(r_{1}\right)-\rho_{\mathrm{B}}\left(r_{2}\right)\right|^{2} d r_{1} d r_{2} \\
=\int\left(\rho_{\mathrm{A}}\left(r_{1}\right)\right)^{2} d r_{1}+\int\left(\rho_{\mathrm{B}}\left(r_{2}\right)\right)^{2} d r_{2} \\
\quad-2 \iint \rho_{\mathrm{A}}\left(r_{1}\right) \rho_{\mathrm{B}}\left(r_{2}\right) d r_{1} d r_{2} \\
=Z_{\mathrm{AA}}+Z_{\mathrm{BB}}-2 Z_{\mathrm{AB}} .
\end{aligned}
$$

Overlap integral is involving the $Z_{\mathrm{AB}}$ between the electronic density of the molecules $\mathrm{A}$ and $\mathrm{B}$, and $Z_{\mathrm{AA}}$ and $Z_{\mathrm{BB}}$ are selfsimilarity of the molecules $A$ and $B$, respectively [65]; using this framework the quantum similarity indexes are defined.

In the QS framework the axiomatic properties of the Euclidean distance can be mentioned and defined according to M. Deza and E. Deza [66] as follows: let $\mathbf{H}$ be a set. A function $G: \mathbf{H} \times \mathbf{H} \rightarrow \mathbf{R}^{+}$is called a distance (or similarity) on $\mathbf{H}$. If and only if $\forall \rho_{A}\left(r_{1}\right), \rho_{B}\left(r_{2}\right) \in \mathbf{H}$, there holds

(i) $D\left(\rho_{\mathrm{A}}\left(r_{1}\right), \rho_{\mathrm{B}}\left(r_{2}\right)\right) \geq 0 \quad$ (non-negativity),

(ii) $D\left(\rho_{\mathrm{A}}\left(r_{1}\right), \rho_{\mathrm{B}}\left(r_{2}\right)\right)=D\left(\rho_{\mathrm{B}}\left(r_{2}\right), \rho_{\mathrm{A}}\left(r_{1}\right)\right)$,

$$
\text { (symmetry), }
$$

(iii) $D\left(\rho_{\mathrm{A}}\left(r_{1}\right), \rho_{\mathrm{B}}\left(r_{2}\right)\right)=0 \quad$ (reflexivity).

Using these mathematical and axiomatic properties in this study the definition of similarity in quantum object sets supported in an pre-Hilbert vector space is explained, where the scalar product and an attached norm are defined [67]. In this sense, one of the most important properties in the MQS field used in this study is the definition of a centroid origin which shifts to choose a reference system within the MQS measures using the fact of their linear independence, according to Carbó-Dorca et al. $[68,69]$.

The most common way to describe the quantum similarity index is by the cosine function, introduced by Besalú. [113] and this index can be expressed mathematically as

$$
\text { Carbó-index }\left(I_{\mathrm{AB}}\right)=\frac{\iint \rho_{\mathrm{A}}\left(r_{1}\right) \rho_{\mathrm{B}}\left(r_{2}\right) d r_{1} d r_{2}}{\sqrt{\int\left(\rho_{\mathrm{A}}\left(r_{1}\right)\right)^{2} d r_{1} \int\left(\rho_{\mathrm{B}}\left(r_{2}\right)\right)^{2} d r_{2}}}
$$

or also in function of the elements of $(\mathbf{Z})$ and an operator $(\boldsymbol{\Omega})$ as

$$
\begin{aligned}
& I_{\mathrm{AB}} \\
& =\frac{\iint \rho_{\mathrm{A}}\left(r_{1}\right) \Omega\left(r_{1}, r_{2}\right) \rho_{\mathrm{B}}\left(r_{2}\right) d r_{1} d r_{2}}{\sqrt{\int \rho_{\mathrm{A}}\left(r_{1}\right) \Omega\left(r_{1}\right) \rho_{\mathrm{A}}\left(r_{1}\right) d r_{1} \int \rho_{\mathrm{B}}\left(r_{2}\right) \Omega\left(r_{2}\right) \rho_{\mathrm{B}}\left(r_{2}\right) d r_{2}}} \\
& =\frac{Z_{\mathrm{AB}}(\boldsymbol{\Omega})}{Z_{\mathrm{AA}}(\boldsymbol{\Omega}) Z_{\mathrm{BB}}(\boldsymbol{\Omega})} .
\end{aligned}
$$

Equations (23) and (24) are mathematically defined in the interval $(0,1]$, where 0 means complete (dis)similarity and 1 the self-similarity and calculates only the measures of "shape similarity." Other alternative of quantum similarity index is the Hodgkin-Richards index (HK) [114], and this index appears naturally when the arithmetic mean is used and can be defined mathematically as

$$
\text { (HR) } I_{\mathrm{AB}}=\frac{2 Z_{\mathrm{AB}}(\boldsymbol{\Omega})}{Z_{\mathrm{AA}}(\boldsymbol{\Omega})+Z_{\mathrm{BB}}(\boldsymbol{\Omega})} \text {. }
$$

However this HR index can be interpreted as a scaled Euclidian distance according to Carbó-Dorca [115]. In this sense, the chemical reactivity analysis of the molecular density functions is made in terms of molecular alignment in the MQS framework.

2.3. Molecular Alignment in the DA Reactions. From chemical reactivity to molecular similarity the arrangement or 


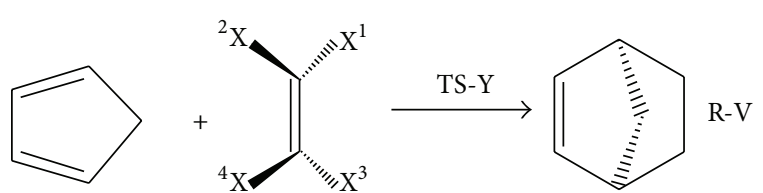

FIGURE 1: The transition structures (TSs) to the reactions (R) between cyclopentadiene (Cp) and ethylene derivatives (Et-nCN) with $n=0,1,2,2$-cis, 2-trans, 3, 4, and their cycloadducts (C), respectively.

alignment of the molecules plays a central role, and the MQS values are strongly dependent on the alignment method considered. Taking into account this dependence many alignment methods have been proposed, ranging from those used in CoMFA and CoMSIA methods which are in three dimensions (3D) and allow obtaining steric, electrostatic, and hydrophobic maps, among others [116]. These methods have been proposed in order to find alignment pattern that yields the best results by molecular alignment; therefore the topogeometrical superposition algorithm alignment method to handle flexible molecules (TGSA-Flex) [117] is used. This method is based on the comparison of the types of atoms and distances between them and the recognition of the largest common substructure in the aligned molecules. These types of search algorithms constitute an important field of scientific interest [118]. In this study, we decided to superimpose the TSs of Figure 1 using the TS-Et for the reaction R-1 as references of these TSs and are indicated in Figure 2.

On the other hand, the TGSA-Rigid alignment method [119] also was used in order to study the electronic and structural flexibility in each DA reactions (see Figure 1) with respect to the TGSA-Flex [117].

\section{Computational Details}

Due to that the DFT provides a powerful unified framework for the rationalization of the chemical system responses front to perturbations (i.e., chemical reactivity). All the molecular structures were optimized and carried out using the Berny analytical gradient optimization method $[120,121]$ with the help of GAUSSIAN 09 suite of programs [122] using DFT methods. The B3LYP exchange-correlation functional [123-125]; together with standard 6-31G(d) base set [126], the orbital energies using $(U) B 3 L Y P / 6-31 G(d)$ level were computed.

B3LYP/6-31G(d) Kohn-Sham wave functions have provided good predictions of potential surface energy (PES) that have been consistent with many experimental results [127-131]. Presently it is known that the B3LYP calculations can illustrate the structure of the TSs in polar DA reactions involving cyclopentadiene, and this is confirmed by the compilation of deuterium secondary kinetic isotope effects and results of quantum chemical calculations for cycloaddition between cyclopentadiene and E-2-phenylnitroethene [131, 132]. Additionally, in this study these results were also tested using the M06-2X/6-311 $+G(d, p)$ method [133].
In this sense, the B3LYP in many cases has replaced the traditional $a b$ initio methods and for this reason was used in this study; additionally this calculation level can be adequate for the purpose of this study, in order to characterize the dispersion energy for the (HOMO) and (LUMO) frontier orbitals which are important on the chemical reactivity in the reactions studied [109-111]. The stationary points were characterized by frequency calculations to verify that all TSs have only one imaginary frequency. The solvent effects of dioxane were taken into account through full optimizations using the polarizable continuum model (PCM) developed by Tomasi's group [110] in the self-consistent reaction field (SCRF) [111].

In this study the CT processes are analyzed in the reactants initially and along each reaction path; in this sense the intrinsic reaction coordinates (IRC) paths to verify the energy profiles connecting each TS with the two minima of the proposed mechanisms using the second-order GonzálezSchlegel integration method were calculated $[134,135]$. In general, when the molecular alignment in the both TGSAFlex and TGSA-rigid programs is executed, the coordinates of the first molecule, considered to be fixed in space, are read and the number of heavy atoms is determined. Then, all interatomic distances are calculated and stored in a matrix that will be later used to retrieve these distance values, thus avoiding recomputing them at later stages. Additionally, both TGSA programs were evaluated by means of parameters as computational time, number of superposed atoms, and the index of fit between the compared structures by Gironés and Carbó-Dorca [117, 119], respectively, which for this reason were used in this study.

On the other hand, to calculate the reactivity descriptors the MolReactivity program, version 1.0 (2014) made by our research group [136-140], was used, taking into account (1)(18), in order to characterize the interaction energy from closed-shell (steric) repulsion, CT from occupied-vacant orbital interactions, and polarization effects, among other reaction parameters. Finally, the MPWB1K hybrid metafunctional was used due to that it is a general functional that includes covalent, partial (TS), hydrogen, and weak bonds. In this sense, it is used in order to validate the thermochemical values and the accuracy of DA reactions that can have interactions obviously beyond the capability of B3LYP (e.g., hydrogen bonding catalysis or $\pi$-stacking) [141].

\section{Results and Discussion}

The reactivity descriptors are defined in DFT $[92,93,97]$ and allow us establish the nonpolar or polar nature on the DA reactions [15-17, 31]. In this study a possible explanation of the electronic reorganization in terms of CT takes the characteristics of a grand canonical ensemble and the considerations for an electrophilic system defined by \{chemical potential $(\mu)$, hardness $(\eta)\}$ in a sea of mobile electrons with zero chemical potential [79] in DFT framework. Taking into account that in the DA reactions studied (see Figure 1) the nucleophile $(\mathrm{Cp})$ is common, and the polar nature can be explained by the electrophilicity increased in the dienophiles and their CT, 


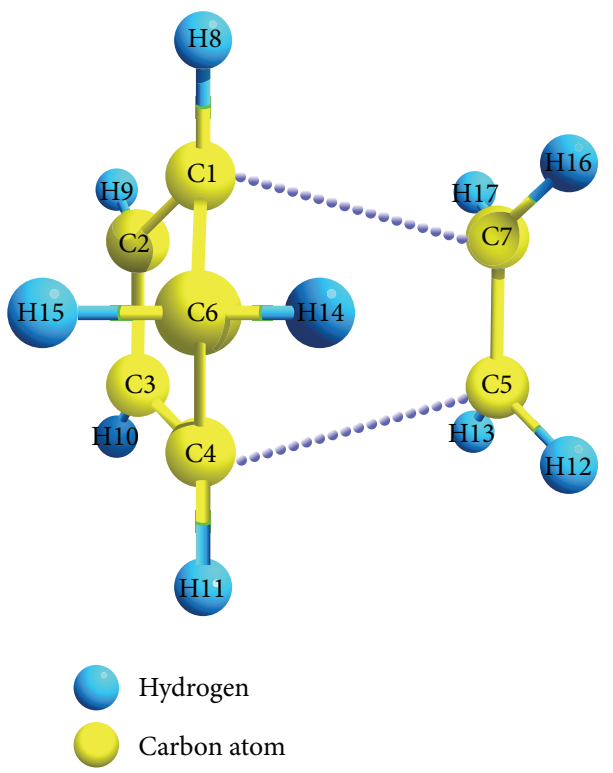

(a)

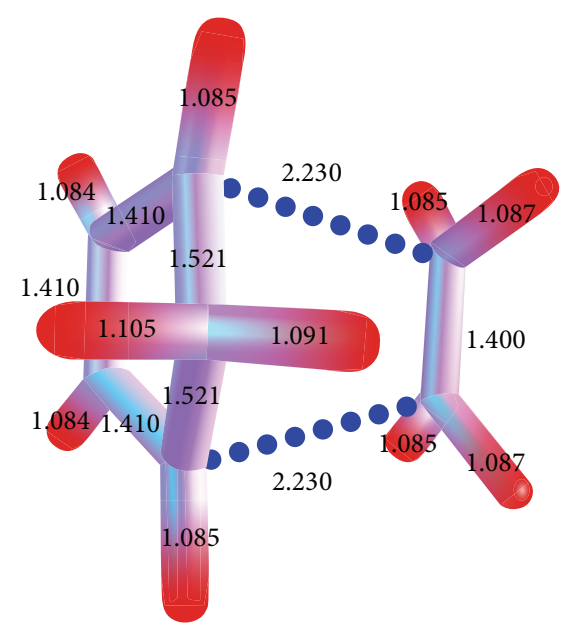

(b)

Figure 2: Concerted TS of $\left(C_{s}\right)$ point group to the reference reaction $(\mathrm{Cp}+\mathrm{Et})$ is used for the molecular superposition in the molecular alignment.

respectively. On the other hand, the dioxane solvation effects on these reactions are carried out. However, such effects have not incidence on the geometric and electronic parameters of the structures according to Domingo et al. [15-17]. In this sense the global and local reactivity indexes are shown in Table 2.

In Table 2 we can see the higher chemical potential associated to the reaction between $(\mathrm{Cp}+4 \mathrm{CN})$ with a values of $\Delta \mu=4.021 \mathrm{eV}$. These results are in agreement with the high experimental reaction rate for this reaction estimated in the order of $10^{7}$, while the lowest potential difference is obtained in the reaction $(\mathrm{Cp}+\mathrm{Et})$ with a value of $\Delta \mu=$ $0.3555 \mathrm{eV}$ and is in agreement with the low experimental reaction rate for this reaction estimated in the order of $10^{-5}$. These values are consistent with the respective hardness and the electrophilicity values, found for the reaction $(\mathrm{Cp}+$ $4 \mathrm{CN}): \Delta \eta=0.724 \mathrm{eV}, \Delta \omega=5.272 \mathrm{eV}$, and for the reaction $(\mathrm{Cp}+\mathrm{Et})$ are $\Delta \eta=1.005 \mathrm{eV}$ and $\Delta \omega=0.0697 \mathrm{eV}$, respectively. These high differences between the values of the $\Delta \eta$ and $\Delta \omega$ are consistent with the experimental reaction rate (see Table 1).

The higher value of $\Delta N_{\max }$ was obtained for the reaction $(\mathrm{Cp}+4 \mathrm{CN})$ with $\Delta N_{\max }=0.8403 e$ (see Table 2$)$ and is in agreement with the high experimental reaction rate estimated in the order of $10^{7}$ and showing a strong polar character; the lowest value is obtained for the reaction of $(\mathrm{Cp}+\mathrm{Et})$ with a value $\Delta N_{\max }=0.0546 e$ showing a nonpolar character, according to the electronic classification of the DA reactions $[1-8,11,12]$. In this sense, the polar character may be related with the zwitterion character associated to the TSs. In order to study CT processes, the local reactivity rates are displayed in Table 3.
The higher values of $f^{+}(r)=0.5000$ are to Et showing higher susceptibility to attack by nucleophile centers associated with Cp (Table 3); however, the electronic reorganizations have a nonpolar path according to $\Delta N_{\max }=0.0546 e$ (see Table 2); whereas the lowest value of $f^{+}(r)=0.2789$ is for $4 \mathrm{CN}$ and has a polar electronic reorganization according to $\Delta N_{\max }=0.8403 e$, these trends from the nonpolarity to polarity are consistent with the local electrophilicity values from $\omega_{1}=0.4275$ for the $4 \mathrm{CN}$ to $\omega_{1}=0.0005$ for the Et. However, when the local electrophilicity is analyzed in the isomers, the following values were found: $2 \mathrm{cCN}$ with $\omega_{1}=$ 0.2043 and of $2 \mathrm{tCN}$ with $\omega_{1}=0.2124$ evidencing higher local electrophilicity character in the transisomer; however, the local CT in the cis-isomer is slightly higher with $\Delta N_{\max 1}=$ $0.1577 e$ whereas for the transisomer it is $\Delta N_{\max 1}=0.1576 e$.

These outcomes are consistent with the experimental trend shown in Table 3. Therefore, in this study we can relate the local trend of the CT in terms of $\Delta N_{\max 1}(k)$ with the experimental reaction rate trend, presenting the origins of the polar character in these DA reactions from $1 \mathrm{CN}$ with $\Delta N_{\max 1}=0.1321 e$ to $\Delta N_{\max 1}=0.2343 e$ for $4 \mathrm{CN}$.

Figure 3(a) shows a high correlation $\left(R^{2}=0.9118\right)$ between the equations model used in this study and the experimental reaction rates. On the other hand, Figure 3(b) also shows good correlation $\left(R^{2}=0.9667\right)$ between the local electrophilicity (17) with respect to the experimental reaction rates; however, these values cannot accurately describe the experimental trend of the $2 \mathrm{tCN}$ and $2 \mathrm{cCN}$ isomers. For this reason, with the intention of analyzing the polar character in the CT, the distortion (quantum similarity) on the TSs with respect to the TS-Et (see Figure 1) from the MQS point of view is analyzed. 


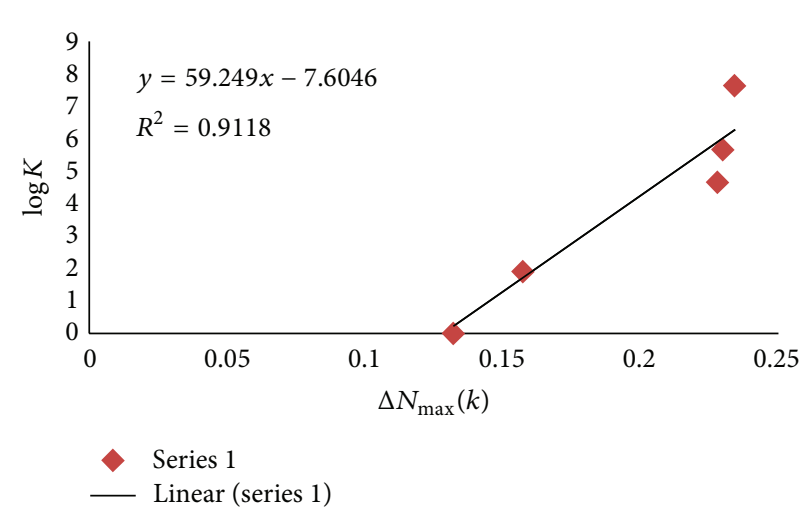

\begin{tabular}{cc}
\hline $\log K^{\mathrm{a}}$ & $\Delta N_{\max }(k)$ \\
\hline 7.6335 & 0.2343 \\
6.0000 & 0.2299 \\
4.6812 & 0.2278 \\
1.9590 & 0.1577 \\
1.9084 & 0.1576 \\
0.0170 & 0.1321 \\
\multicolumn{2}{c}{ Standard deviation ${ }^{\mathrm{b}}$} \\
1.3804 & 0.0031 \\
1.5015 & 0.0033 \\
2.3628 & 0.0366 \\
2.4667 & 0.0400 \\
2.8336 & 0.0457 \\
\hline a pk $=\log K$ & \\
\multicolumn{2}{c}{} \\
\end{tabular}

(a) $\log K$ versus local CT $\left(\Delta N_{\max 1}(k)\right)$

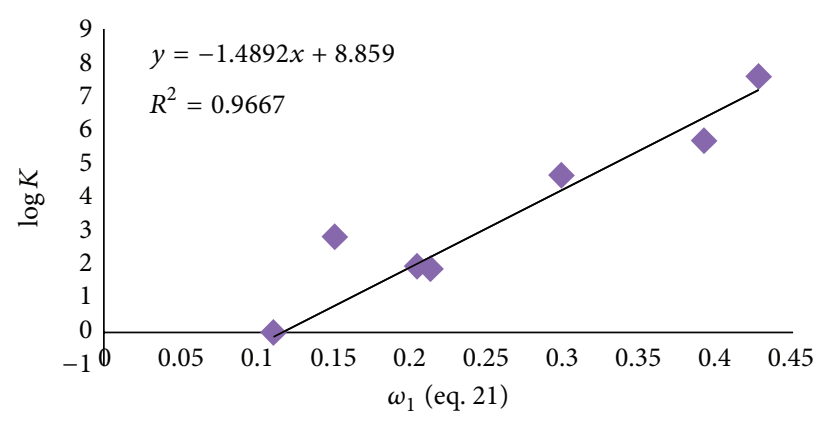

\begin{tabular}{cc}
\cline { 2 - 2 } $\log K^{\mathrm{a}}$ & $\omega_{1}(17)^{\mathrm{b}}$ \\
\hline 7.6335 & 0.4275 \\
6.0000 & 0.3912 \\
4.6812 & 0.2992 \\
1.9590 & 0.2043 \\
1.9084 & 0.2124 \\
0.0170 & 0.1108 \\
\multicolumn{2}{c}{ Standard deviation ${ }^{\mathrm{c}}$} \\
1.3804 & 0.0257 \\
1.5014 & 0.0661 \\
2.3627 & 0.0999 \\
2.4667 & 0.1014 \\
2.8340 & 0.1210 \\
\hline${ }^{\mathrm{a}} \mathrm{pk}=\log K$ & \\
${ }^{\mathrm{b}}$ Local electrophilic $\left(\omega_{1}\right)$ \\
c Standard deviation with respect to TS reference
\end{tabular}

(b) $\log K$ versus local electrophilicity $\left(\omega_{1}\right)$

Figure 3: Correlation analysis (a) $\log K$ versus local CT $\left(\Delta N_{\max 1}(k)\right)$ and (b) $\log K$ versus local electrophilicity $\left(\omega_{1}\right)$ with the standard deviation, respectively.

In order to study the electronic and structural flexibility effects due to the systematic variations of the cyan groups $(-\mathrm{CN})$, actually, the distortion models in pericyclic reactions are important tools in the structural and electronic analysis on TSs and energy profiles according to Ess et al. [142-144]. The quantum distortion in this study is described with the similarity indexes; therefore a high quantum distortion of overlap and coulomb means (dis)similarity and the largest Euclidean distances, taking into account that the similarity indexes are mathematically defined in the interval $(0,1]$ where 0 means complete (dis)similarity and 1 the selfsimilarity.

In order to characterize the steric and electronic effects using TGSA-Flex alignment method the structural distortion can be associated with the MQS overlap and the electronic distortion can be associated with the MQS-coulomb. This TGSA-Flex method is compared with the TGSA-rigid. As pointed out by Carbó-Dorca $[77,78]$ the molecular densities functions should be referred to a common origin and therefore first density differences are used which leads to consider the distances between electronic densities, taking into account that the MQS varies with the origin selected and the Euclidean distances not. In Table 4 the overlap indexes values and the Euclidean distance of overlap are shown. In Tables 5 and 6 the coulomb indexes values are shown, respectively. Finally, the Euclidean distance of coulomb using TGSA-rigid is depicted in Table 7, in order to relate the MQS of the TSs with the TS-Et reference state.

The molecular quantum similarity values using the overlap operator are shown in Table 4 . The higher value of quantum similarity of 0.7045 is obtained when the TS$4 \mathrm{CN}$ with TS-Et are compared with a Euclidean distance of overlap of 2.3096 (see Table 5), quantifying the effects from the structural point of view due to the presence of the 4 cyan $(-4 \mathrm{CN})$ groups in the TS-4CN with respect to ethylene.

The lowest values of quantum similarity 0.9284 are obtained when the TS-3CN is compared with TS-4CN and a Euclidean distance of 1.2073 (Table 5). Additionally, the quantum similarity of TS-4CN with respect to other members of the series analyzed shows the same experimental trend. This similarity trend also can be observed in the Euclidean distance values of overlap (Table 5). With the aim of study the 
TABLE 2: Global reactivity descriptors in electronvolt $(\mathrm{eV})$ and the softness in $\left(\mathrm{eV}^{-1}\right)$.

\begin{tabular}{lccccc}
\hline $\mathrm{C}^{\mathrm{a}, \mathrm{b}}$ & $\mu(\mathrm{eV})^{\mathrm{c}}$ & $\eta(\mathrm{eV})^{\mathrm{d}}$ & $S\left(\mathrm{eV}^{-1}\right)^{\mathrm{e}}$ & $\omega(\mathrm{eV})^{\mathrm{f}}$ & 0.8261 \\
\hline $\mathrm{Cp}$ & -3.0171 & 2.7546 & 0.3630 & 6.0984 & 0.8403 \\
$4 \mathrm{CN}$ & -7.0381 & 2.0306 & 0.4925 & 3.9124 & 0.6315 \\
$3 \mathrm{CN}$ & -6.4193 & 2.6331 & 0.3798 & 2.6770 & 0.4585 \\
$2 \mathrm{CN}$ & -5.6441 & 2.9749 & 0.3361 & 2.7359 & 0.4636 \\
$2 \mathrm{cCN}$ & -5.6200 & 2.8861 & 0.3465 & 2.8380 & 0.4788 \\
$2 \mathrm{tCN}$ & -5.7124 & 2.8745 & 0.3479 & 1.6899 & 0.2789 \\
$1 \mathrm{CN}$ & -4.6949 & 3.2609 & 0.3067 & 0.7564 & 0.0546 \\
$\mathrm{Et}$ & -3.3726 & 3.7593 & 0.2660 & & $\mathrm{c}$ \\
\hline
\end{tabular}

${ }^{\mathrm{a} C}$ : compound.

${ }^{\mathrm{b}}$ Exp. trend.

${ }^{\mathrm{c}}$ Chemical potential $(\mu)$.

${ }^{\mathrm{d}}$ Hardness $(\eta)$.

${ }^{\mathrm{e}}$ Softness $(S)$.

${ }^{\mathrm{f}}$ Global electrophilicity $(\omega)$.

${ }^{\mathrm{g}}$ Saturation condition $\left(\Delta N_{\max }\right)(11)$

TABLE 3: Local reactivity descriptors.

\begin{tabular}{llccccc}
\hline $\mathrm{C}^{\mathrm{a}, \mathrm{b}}$ & $f_{1}^{+}(\vec{r})^{\mathrm{c}}$ & $\omega_{1}{ }^{\mathrm{d}}$ & $\Delta N_{\max 1}{ }^{\mathrm{e}}$ & $f_{2}^{+}(\vec{r})$ & $\omega_{2}$ & $\Delta N_{\max 2}$ \\
\hline $4 \mathrm{CN}$ & 0.2789 & 0.4275 & 0.2343 & 0.2789 & 0.4275 & 0.2343 \\
$3 \mathrm{CN}$ & 0.3642 & 0.3912 & 0.2299 & 0.2686 & 0.2885 & 0.1448 \\
$2 \mathrm{CN}$ & 0.4968 & 0.2992 & 0.2278 & 0.2404 & 0.2043 & 0.1102 \\
$2 \mathrm{cCN}$ & 0.3402 & 0.2043 & 0.1577 & 0.3402 & 0.32124 & 0.1576 \\
$2 \mathrm{tCN}$ & 0.3292 & 0.2124 & 0.1576 & 0.3001 & 0.0702 & 0.0837 \\
$1 \mathrm{CN}$ & 0.4735 & 0.1108 & 0.1321 & 0.5000 & 0.0005 & 0.0273 \\
$\mathrm{Et}$ & 0.5000 & 0.0005 & 0.0273 & & & \\
\hline
\end{tabular}

${ }^{\mathrm{a}} \mathrm{C}$ : compound.

${ }^{\mathrm{b}}$ Exp. trend.

${ }^{\mathrm{c}}$ Fukui function.

${ }^{d}$ Local electrophilicity $\left(\omega_{k}\right)(17)$.

${ }^{\mathrm{e}}$ Local saturation condition $\left(\Delta N_{\max }(k)\right)(18)$.

distortion effects in Table 6 is shown the coulomb similarity values together with the Euclidean distance of coulomb.

In Table 6 the quantum similarity values using the coulomb operator are shown, and the higher similarity value of 0.9277 is found between the TS-Et and TS-4CN with a Euclidean distance of 15.4726 (Table 7). The lowest value of similarity of 0.9867 is found between TS-3CN and TS$4 \mathrm{CN}$ with a Euclidean distance of 5.7883 (Table 7). The values associated with the quantum similarity distortion of Et (reference state) with other members of the series are in agreement with the experimental trend (see Table 1). These values allow us associate the higher distortion of $4 \mathrm{CN}$ with the higher fluctuation of the reaction rates estimated in $10^{7}$ for $4 \mathrm{CN}$, from the structural and electronic distortion point of view (see Tables 4-7).

The main difference between the TGSA-rigid and TGSAFlex is that the TGSA-rigid was originally designed to superpose rigid molecules simply based on atomic numbers, molecular coordinates, and connectivity. While the algorithm TGSA-flex is further developed to enable handling rotations around single bonds, in this way, common structural features, which were not properly aligned due to conformational causes, can be brought together; thus improving the molecular similarity picture of the final alignment, these effects can be important on the quantum similarity in the cis- and transisomers. In this sense, the values associated with the structural flexibility on the quantum similarity of overlap using the Carbó-Dorca index (24) are shown in Table 8.

In Table 8 the higher structural flexibility value of 0.5088 is found between the TS- $4 \mathrm{CN}$ and TS-2tCN, the lowest similarity value of 0.8348 we can see between the TS-2tCN and TS-1CN. The similarity to the TS- $2 \mathrm{cCN}$ with TS- $1 \mathrm{CN}$ is estimated in 0.6644 , presenting large differences in the structural flexibility on the TS-2tCN and TS- $2 \mathrm{cCN}$, respectively. Another example of this fact is found when the TS-Et reference with the TS-2cCN obtaining 0.7193 is compared, whereas for TS-Et with TS-2tCN it is 0.6899 , presenting higher structural distortion. These results show that the geometric isomers are distorted by the structural flexibility effects, with the aim of comparing the structural distortion on the isomers using the Hodgkin-Richards indexes of overlap using (25) in Table 9, and this index can be related to the information on the angle subtended between two electronic densities along these DA cycloadditions.

In Table 9 the higher value of 0.5008 was found between the TS-2tCN and TS-4CN, and the lowest value of 0.8288 was found between the TS-2tCN with TS-1CN and is in agreement with the values found using the Carbó-Dorca 
TABLE 4: Molecular quantum similarity matrix of overlap, using the TGSA-rigid alignment method.

\begin{tabular}{lcccccr}
\hline $\mathrm{S}^{\mathrm{a}, \mathrm{b}}$ & TS-4CN & TS-3CN & TS-2CN & TS-2cCN & TS-2tCN & TS-1CN \\
\hline TS-4CN & 1.0000 & & & & & \\
TS-3CN & 0.9284 & 1.0000 & & & & \\
TS-2CN & 0.8598 & 0.8318 & 1.0000 & & & \\
TS-2cCN & 0.8580 & 0.9171 & 0.8183 & 1.0000 & & \\
TS-2tCN & 0.8499 & 0.9154 & 0.8222 & 0.8277 & 1.0000 & 1.0000 \\
TS-1CN & 0.7829 & 0.8373 & 0.9021 & 0.9020 & 0.9086 & 0.8836 \\
TS-Et & 0.7045 & 0.7483 & 0.8075 & 0.8072 & 0.8075 & 1.0000 \\
\hline
\end{tabular}

${ }^{a}$ S: state (Table 1).

${ }^{\mathrm{b}}$ Exp. trend.

TABLE 5: Molecular quantum similarity matrix using the overlap Euclidean distances, using the TGSA-rigid alignment method.

\begin{tabular}{lcccccc}
\hline $\mathrm{S}^{\mathrm{a}, \mathrm{b}}$ & TS-4CN & TS-3CN & TS-2CN & TS-2cCN & TS-2tCN & TS-1CN \\
\hline TS-4CN & 0.0000 & & & & & \\
TS-3CN & 1.2073 & 0.0000 & & & & \\
TS-2CN & 1.6597 & 1.6932 & 0.0000 & & & \\
TS-2cCN & 1.6697 & 1.2024 & 1.6647 & 0.0000 & & 0.00000 \\
TS-2tCN & 1.7119 & 1.2136 & 1.6468 & 1.6210 & 1.2136 & 0.000 \\
TS-1CN & 2.0229 & 1.6494 & 1.6932 & 1.2024 & 1.6301 & 2.0022 \\
TS-Et & 2.3096 & 2.0023 & 1.6597 & 11.6697 & & 0.0000 \\
\hline
\end{tabular}

${ }^{a}$ S: state (Table 1).

${ }^{\mathrm{b}}$ Exp. trend.

TABLE 6: Molecular quantum similarity matrix of coulomb, using the TGSA-rigid alignment method.

\begin{tabular}{lcccccc}
\hline$S^{\mathrm{a}, \mathrm{b}}$ & TS-Et & TS-1CN & TS-2tCN & TS-2cCN & TS-2CN & TS-3CN \\
\hline TS-Et & 1.0000 & & & & & \\
TS-1CN & 0.9733 & 1.0000 & & & & \\
TS-2tCN & 0.9561 & 0.9789 & 1.0000 & & & \\
TS-2cCN & 0.9529 & 0.9788 & 0.9659 & 1.0000 & & 1.0000 \\
TS-2CN & 0.9528 & 0.9795 & 0.9648 & 0.9612 & 0.9746 & 1.0000 \\
TS-3CN & 0.9394 & 0.9629 & 0.9842 & 0.9835 & 0.9703 & 0.9867 \\
TS-4CN & 0.9277 & 0.9518 & 0.9733 & 0.9693 & & 1.0000 \\
\hline
\end{tabular}

${ }^{a}$ S: state (Table 1).

${ }^{\mathrm{b}}$ Exp. trend.

TABLE 7: Molecular quantum similarity matrix using the coulomb Euclidean distances, using the TGSA-rigid alignment method.

\begin{tabular}{lcccccc}
\hline$S^{\mathrm{a}, \mathrm{b}}$ & TS-Et & TS-1CN & TS-2tCN & TS-2cCN & TS-2CN & TS-3CN \\
\hline TS-Et & 0.0000 & & & & & \\
TS-1CN & 5.7860 & 0.0000 & & & & \\
TS-2tCN & 9.0121 & 5.7890 & 0.0000 & & & \\
TS-2cCN & 9.2795 & 5.7677 & 6.7312 & 0.0000 & & \\
TS-2CN & 9.2812 & 5.7926 & 6.8394 & 7.1929 & 0.0000 & 0.0000 \\
TS-3CN & 12.3742 & 9.2595 & 5.7624 & 5.7965 & 6.8474 & 5.7883 \\
TS-4CN & 15.4726 & 12.3544 & 5.7624 & 9.3056 & 9.2301 & 0.0000 \\
\hline
\end{tabular}

${ }^{\mathrm{a} S}$ : state (Table 1).

${ }^{\mathrm{b}}$ Exp. trend. 
TABLE 8: Molecular quantum similarity Carbó-Dorca matrix of overlap, using the TGSA-Flex alignment method.

\begin{tabular}{lcccccc}
\hline$S^{\mathrm{a}, \mathrm{b}}$ & TS-4CN & TS-3CN & TS-2CN & TS-2cCN & TS-2tCN & TS-1CN \\
\hline TS-4CN & 1.0000 & & & & & \\
TS-3CN & 0.6959 & 1.0000 & & & & \\
TS-2CN & 0.6224 & 0.5908 & 1.0000 & & & \\
TS-2cCN & 0.5599 & 0.6647 & 0.5343 & 1.0000 & & \\
TS-2tCN & 0.5088 & 0.5908 & 0.6259 & 0.7124 & 1.0000 & 1.0000 \\
TS-1CN & 0.5259 & 0.6722 & 0.6722 & 0.6644 & 0.8348 & 0.7488 \\
TS-Et & 0.5536 & 0.6029 & 0.7197 & 0.7193 & 0.6899 & 1.0000 \\
\hline
\end{tabular}

${ }^{a}$ S: state (Table 1).

${ }^{\mathrm{b}}$ Exp. trend.

TABLE 9: Molecular quantum similarity Hodgkin-Richards of overlap, using the TGSA-Flex alignment method.

\begin{tabular}{lcccccc}
\hline S, $\mathrm{b}$ & TS-4CN & TS-3CN & TS-2CN & TS-2cCN & TS-2tCN & TS-1CN \\
\hline TS-4CN & 1.0000 & & & & & \\
TS-3CN & 0.6936 & 1.0000 & & & & \\
TS-2CN & 0.6125 & 0.5880 & 1.0000 & & \\
TS-2cCN & 0.5511 & 0.6616 & 0.5343 & 1.0000 & & \\
TS-2tCN & 0.5008 & 0.6259 & 0.6259 & 0.7124 & 1.0000 & 1.0000 \\
TS-1CN & 0.5031 & 0.6359 & 0.6673 & 0.6596 & 0.8288 & 0.7393 \\
TS-Et & 0.4997 & 0.6392 & 0.6922 & 0.6918 & 0.6635 & 1.0000 \\
\hline
\end{tabular}

${ }^{\mathrm{a}}$ S: state (Table 1).

${ }^{\mathrm{b}}$ Exp. trend.

index (see Table 8). For the other isomer TS- $2 \mathrm{cCN}$ shows low similarity of 0.6918 when it is compared with the TS-Et reference state; however, the TS-2tCN shows more similarity with 0.6635 . These values have significant differences by flexibility effects between the two geometric isomers; another example of this fact is found comparing the TS-4CN with respect to TS-2cCN (0.5511) and for the TS-2tCN (0.5008). Therefore, we can associate this diminution in the reaction rate with quantum similarity effects.

In Figure 4 a high correlation $\left(R^{2}=0.9499\right)$ between the Carbó-Dorca and Hodgkin-Richards index was found. Showing a structural consistency on the TSs is studied. To analyze the electronic flexibility in the TSs, in Tables 10 and 11, the coulomb Carbó-Dorca (24) and Hodgkin-Richards indexes (25) are studied, respectively.

In Table 10 the higher electronic distortion value of 0.8855 using the coulomb operator is between the TS-4CN and TS-Et states and is in agreement with the electronic distortion of overlap using the TGSA-Flex alignment method (see Table 8), so we can associate this distortion increased of the TS-4CN with the high experimental rate constant estimated in $10^{7}$. On the other hand, the reference state TS-Et has the lowest distortion when it is compared with the TS-1CN state. These distortion results to the TS-Et state are in agreement with the experimental trend $(4 \mathrm{CN}$ $>3 \mathrm{CN}>2 \mathrm{CN}>2 \mathrm{cCN}>2 \mathrm{tCN}>1 \mathrm{CN})$. Therefore, this electronic flexibility study quantifies the degree of distortion on the TSs in systematic form, from the TS-Et to TS-4CN (see Figure 1). In order to compare the Carbó-Dorca values with respect to the Hodgkin-Richards values in Table 11 the MQS-coulomb using the Hodgkin-Richards index is shown.

Comparing the Hodgkin-Richards index using the coulomb operator with those obtained in Table 10 using the Carbó-Dorca index, this latter shows lowest quantum similarity values (values close to 0.00 ), and therefore more distortion effects can be characterized in this way. Figure 5 shows the correlation between the two electronic distortion indexes.

In Figure 5, this high correlation (0.9483) shows the Hodgkin-Richards index as a scaled distance according to Carbó-Dorca [115] is consistent with the Euclidean distance trends from the TS-4CN to TS-Et (see Tables 5 and 7).

In order to relate the CT with the electronic distortion using quantum similarity in the DA reactions studied (see Figure 1). Figure 6 shows the relation between the electronic quantum similarity of coulomb and CT in the DA reactions. According to Bultinck et al. [72] naturally, there is a correlation between distortion (quantum similarity) of coulomb and chemical reactivity; in this sense new insights on the role of $\mathrm{CT}$ in the electronic distortion are shown.

Figure 6 shows acorrelation $\left(R^{2}=0.7127\right)$ between CarbóDorca distortion and CT and their standard deviation with respect to the TS-Et reference state. Such effects have direct responses in the electronic density. In this sense, we can relate the trend found in the zwitterion character with a high distortion on the electronic density associated with the Carbó-Dorca similarity index. Therefore, we can associate 


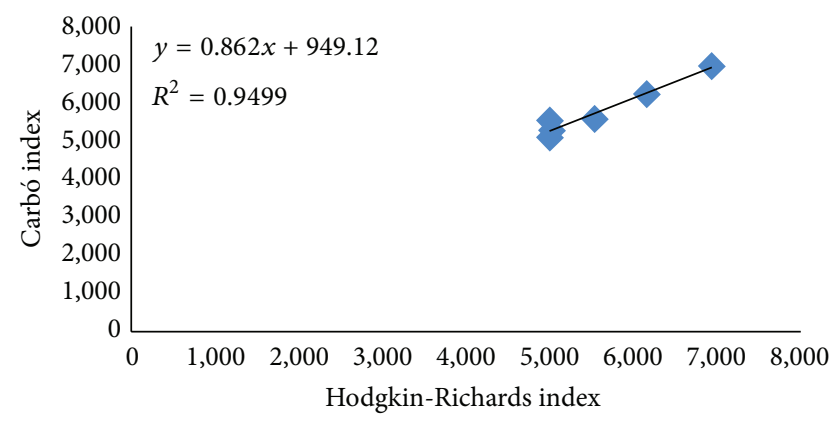

\begin{tabular}{ccc}
\cline { 2 - 2 } $\mathrm{CI}^{\mathrm{a}}$ & $\mathrm{H}-\mathrm{KI}^{\mathrm{a}}$ \\
\hline 10.000 & 10.000 \\
6.959 & 6.936 \\
6.224 & 6.125 \\
5.599 & 5.511 \\
5.088 & 5.008 \\
5.259 & 5.031 \\
5.536 & 4.997 \\
Standard deviation ${ }^{\mathrm{c}}$ \\
2.1503 & 2.1666 \\
2.0019 & 2.0437 \\
1.9505 & 1.9921 \\
1.9344 & 1.9718 \\
1.8374 & 1.8930 \\
1.7181 & 1.8115 \\
\hline a Carbó-Dorca index \\
b ${ }^{\mathrm{b}}$ Hodgkin-Richards index \\
${ }^{\mathrm{c}}$ Standard deviation with respect to TS reference
\end{tabular}

FIgure 4: Carbó-Dorca index versus Hodgkin-Richards index using the overlap operator for the TSs (see Figure 1). Note: in this graphical the Carbó-Dorca and Hodgkin-Richards indexes are normalized from 0 to $100 \%$, with the standard deviation, respectively.

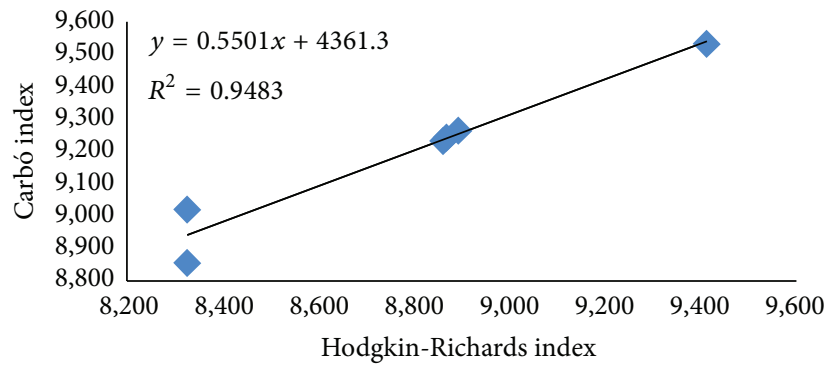

\begin{tabular}{cc}
\hline $\mathrm{CI}^{\mathrm{a}}$ & $\mathrm{H}^{\mathrm{a}} \mathrm{KI}^{\mathrm{a}}$ \\
\hline 10.000 & 10.000 \\
9.531 & 9.413 \\
9.263 & 8.894 \\
9.242 & 8.862 \\
9.238 & 8.859 \\
9.020 & 8.326 \\
8.855 & 8.326 \\
\multicolumn{2}{c}{ Standard deviation } \\
\\
0.3316 & 0.4151 \\
0.3730 & 0.5533 \\
0.3528 & 0.5351 \\
0.3287 & 0.5023 \\
0.3434 & 0.5752 \\
0.3715 & 0.5937 \\
\hline
\end{tabular}

${ }^{a}$ Carbó-Dorca index

${ }^{\mathrm{b}}$ Hodgkin-Richards index

${ }^{c}$ Standard deviation with respect to TS reference

FIgURE 5: Carbó-Dorca index versus Hodgkin-Richards index using the coulomb operator for the TSs (see Figure 3). Note: in this graphical the Carbó-Dorca and Hodgkin-Richards indexes are normalized from 0 to $100 \%$, with the standard deviation, respectively.

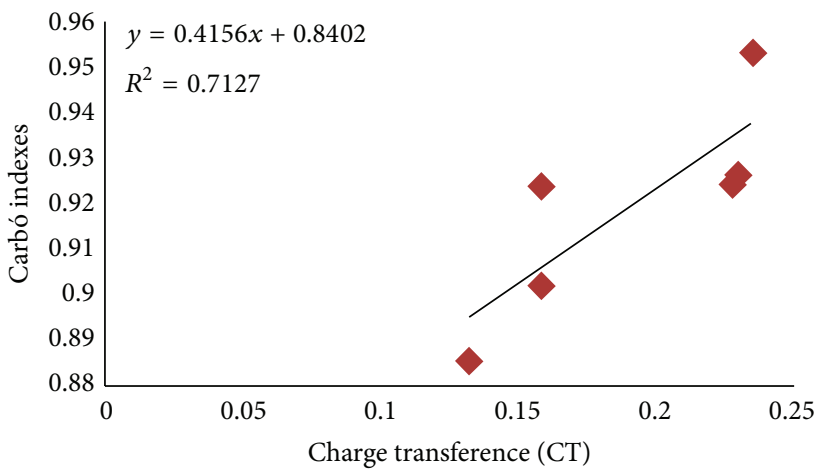

\begin{tabular}{cc}
\hline${ }^{\mathrm{a}}$ Carbó I. ${ }^{\mathrm{a}}$ & $\mathrm{CT}^{\mathrm{b}}$ \\
\hline 0.9531 & 0.2343 \\
0.9263 & 0.2299 \\
0.9242 & 0.2278 \\
0.9238 & 0.1577 \\
0.902 & 0.1576 \\
0.8855 & 0.1321 \\
\multicolumn{2}{c}{ Standard deviation ${ }^{\mathrm{c}}$} \\
0.0190 & 0.0031 \\
0.0161 & 0.0033 \\
0.0142 & 0.0366 \\
0.0186 & 0.0401 \\
0.0231 & 0.0457 \\
\hline
\end{tabular}

${ }^{\mathrm{a}}$ Carbó index

${ }^{\mathrm{b}}$ Charger transfer (CT)

${ }^{\mathrm{c}}$ Standard deviation with respect to TS reference

FIgURE 6: Correlation analysis between Carbó-Dorca index and charge transfer CT in the reactions of Table 1. Note: in this graphical the Carbó-Dorca indexes are normalized from 0 to $100 \%$, with the standard deviation, respectively. 
TABLE 10: Molecular quantum similarity Carbó-Dorca matrix of coulomb, using the TGSA-Flex alignment method.

\begin{tabular}{lcccccc}
\hline S, $\mathrm{b}$ & TS-Et & TS-1CN & TS-2tCN & TS-2cCN & TS-2CN & TS-3CN \\
\hline TS-Et & 1.0000 & & & & & \\
TS-1CN & 0.9531 & 1.0000 & & & & \\
TS-2tCN & 0.9263 & 0.9648 & 1.0000 & & & \\
TS-2cCN & 0.9242 & 0.9598 & 0.9403 & 1.0000 & & \\
TS-2CN & 0.9238 & 0.9531 & 0.9357 & 0.9286 & 0.0000 & 1.0000 \\
TS-3CN & 0.9020 & 0.9366 & 0.9653 & 0.9656 & 0.9417 & 0.9722 \\
TS-4CN & 0.8855 & 0.9164 & 0.9439 & 0.9440 & 0.9468 & 1.0000 \\
\hline
\end{tabular}

${ }^{a}$ S: state (Table 1).

${ }^{\mathrm{b}}$ Exp. trend.

TABLE 11: Molecular quantum similarity matrix of coulomb, using the TGSA-Flex alignment method.

\begin{tabular}{lcccccc}
\hline$S^{\mathrm{a}, \mathrm{b}}$ & TS-Et & TS-1CN & TS-2tCN & TS-2cCN & TS-2CN & TS-3CN \\
\hline TS-Et & 1.0000 & & & & & \\
TS-1CN & 0.9413 & 1.0000 & & & & \\
TS-2tCN & 0.8894 & 0.9568 & 1.0000 & & & \\
TS-2cCN & 0.8862 & 0.9513 & 0.9403 & 1.0000 & & \\
TS-2CN & 0.8859 & 0.9508 & 0.9357 & 0.9286 & 1.0000 & 1.0000 \\
TS-3CN & 0.8326 & 0.9084 & 0.9586 & 0.9594 & 0.9356 & 0.9252 \\
TS-4CN & 0.8326 & 0.8632 & 0.9215 & 0.9225 & 0.9252 & 1.0000 \\
\hline
\end{tabular}

${ }^{\mathrm{a}} \mathrm{S}$ : state (Table 1).

${ }^{\mathrm{b}}$ Exp. trend.

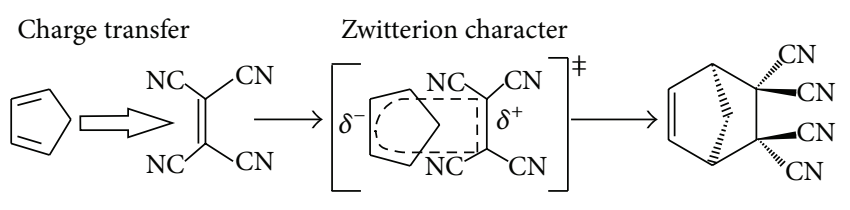

FIGURE 7: Zwitterion status in polar reaction is reported in this study. This electronic reorganization is due to polarization effects on the (CT).

CT with the electronic reorganization and the zwitterion character in these DA reactions (see Table 1) (Figure 7).

In Figure 7 we can associate the zwitterion character with the value of $\Delta N_{\max }=0.8403 e$ (see Table 2) formed by the increases of CT (polar character) reported in this study, and that can be related to the electronic distortion (quantum similarity). This zwitterion character is the first step to the formation of the aromatic nature in the TSs of the polar reactions (R-2 to R-7); see Table 1 . The aromatic nature of these TSs has been confirmed theoretically using geometry-based indices such as the harmonic oscillator model of aromaticity (HOMA), the para-delocalization indices (PDI) $[145,146]$, the nucleus-independent chemical shift (NICS), and the magnetic susceptibility exaltations [147]. Additionally, this study presents new consideration on the analysis of CT in the interaction energy, taking into account that the CT is part of the interaction energy, with the molecular polarization, the closed-shell repulsion, and the dispersion according to Ess et al. [142-144], relating the electronic and structural quantum distortion from the MQS, in terms of the cyano substitutions.

Taking into account the correlation $\left(R^{2}=0.7127\right)$ between Carbó-Dorca distortion and CT (Figure 6), in this study the CT $\left(\Delta N_{\max }\right)$ with the electronic quantum similarity of coulomb to describe the character polar trend using (26) is related. Taking the TS-4CN as a reference:

$$
\begin{aligned}
& \left\{\Delta N_{\max }(\mathrm{TS} 4 \mathrm{CN})\right\}\{\mathrm{MQS} \text { (Coulomb) }\} \\
& =\text { Character polar trend }
\end{aligned}
$$

with

$$
\left\{\Delta N_{\max }(\mathrm{TS} 4 \mathrm{CN})\right\}=\{0.8403\}
$$

(see Table 2). Consider

$$
\{\text { MQS }(\text { Coulomb })\}=\{0<\operatorname{MQS}(\text { Coulomb })<1\}
$$

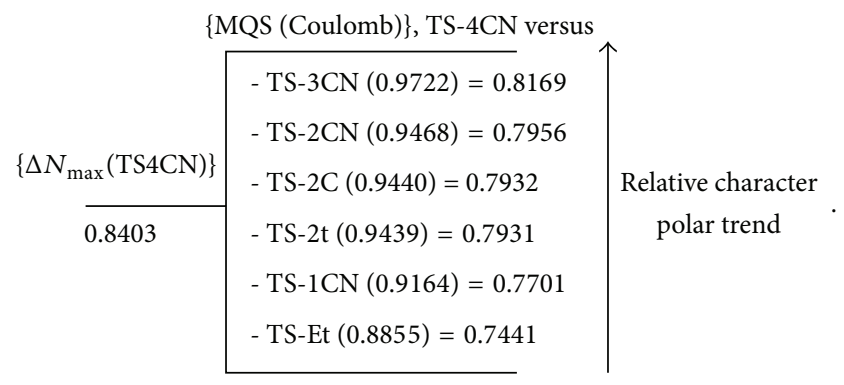



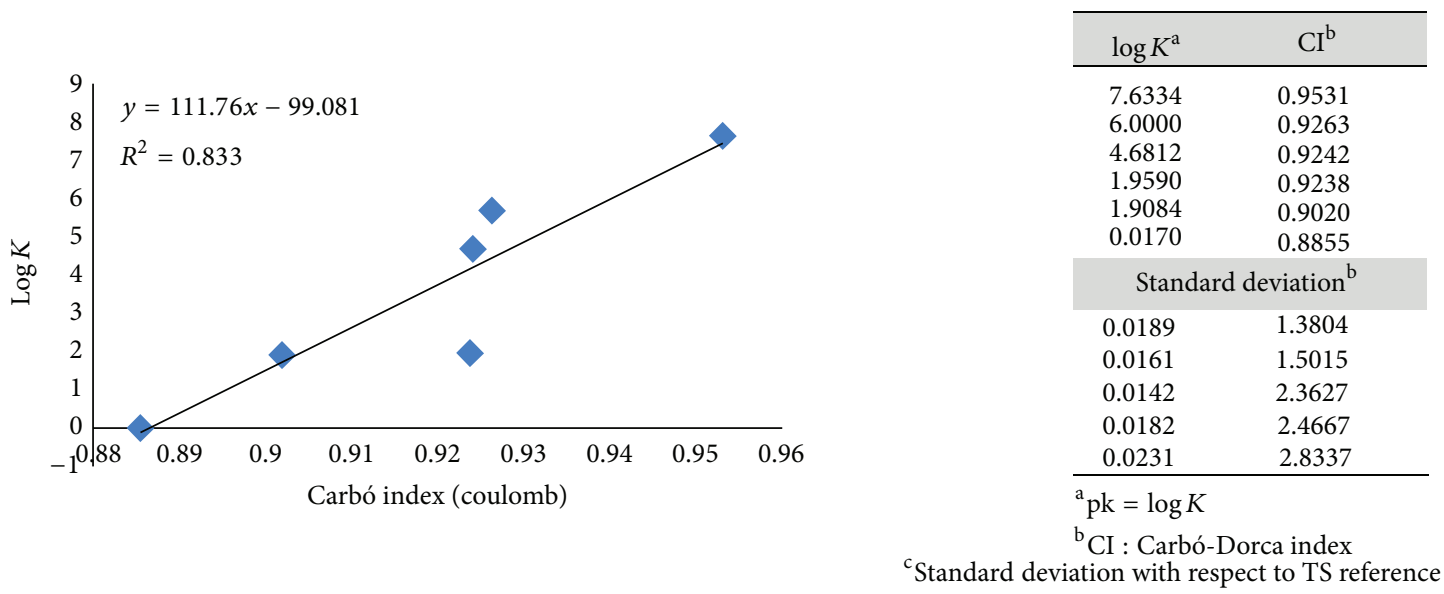

Figure 8: Carbó-Dorca index of Coulomb versus experimental rate constants (see Table 1). Note: in this graphical the Carbó-Dorca indexes are normalized from 0 to $100 \%$, with the standard deviation, respectively.

In (29) the MQS values of coulomb are in Table 10 and we can see the character polar trend along the reactions with respect to TS-4CN and the relative character polar along the DA reactions is a possible form of study.

With the aim of study the electronic distortion and the experimental rate constant trend (see Table 1) is shown in Figure 8 with a high correlation $R^{2}=0.8330$ between the Carbó-Dorca index of coulomb and the natural $\log (\log K=$ $\left.P_{K}\right)$.

According to the finding of Geerlings et al. [97, 148], Figure 8 depicted an alternative relation between the CarbóDorca indexes and chemical reactivity descriptors. One of the remaining problems in this approach is the orientation, translational, and conformational dependence of $Z$ (see (24) and (25)) on the measurement of the MQS; however, this problem was resolved using the autocorrelation function concept of the property considered that for this study is the CT along the DA reactions and such autocorrelation was tested with the standard deviation, respectively. Therefore this result shows a possible way of unification of the chemical reactivity and QS in DFT framework $[148,149]$. In this sense, we can think that this hybrid methodology (joining the MQS with chemical reactivity) provides new insights for the electronic systematization of the DA reactions in the DFT framework, which is an open problem in organic physical chemistry.

A molecular orbital analysis in the DA reactions studied can take into account that the concerted inter- and intramolecular multicenter $\pi$ interactions can be related to the nodal properties (symmetry) of the $\operatorname{HOMO}(\pi)$ and LUMO $\left(\pi^{*}\right)$ frontier orbitals. In this sense, the regiospecificity of such DA interactions can be defined by the molecular polarization parallel to the nodal plane of the orbitals produced by the $(\pi)$ and $\left(\pi^{*}\right)$ DA interactions; therefore, the stereospecificity of such interactions can be associated with the electronic distortion perpendicular to the nodal plane of the orbitals produced by the HOMO-1 $(\sigma)$, HOMO $(\pi)$, LUMO $\left(\pi^{*}\right)$, and LUMO $+1\left(\sigma^{*}\right)$ interactions mixed, according to "principle of Orbital Distortion" [150], and these electronic interactions exceed to the steric effects, yielding the bonds in the cycloadducts respective. These results are consistent with the stereoselectivity analysis reported by Houk et al. [151].

On the other hand, the zwitterionic character and the molecular polarization reported in this study in terms of a grand canonical ensemble can be understood as a relative increase in the number of available microstates in the molecular space producing chemical potential differences and promoting the electron transfer from regions of higher potential to regions of lower chemical potential. Additionally, the CT related with the MQS allows understanding the origin of the polar character using the quantum similarity. Finally, in the TSs when the CT in the electronic reorganization increases, the ionic character of the bonds formed decreases; therefore, the force constants increase and we can relate the polar character with the bond force constants in these DA reactions.

On the other hand, in this study the four features on similarities sugared by Rouvray et al. [152-155] analogies, complementarities, and equivalence and scaling relationships for the role of molecular similarity in the chemical and physical sciences were exploited, exploring a possible methodology to understand the similarity on the chemical reactivity and consistency with the experimental results, which today is a bottleneck in the MQS field.

\section{Conclusions and Perspective}

In this study, the CT processes in a series of reactions between cyclopentadiene $(\mathrm{Cp})$ with cyano substitution on ethylene were analyzed, proposing a possible electronic systematization to the DA reactions. The analysis of the CT takes place initially in the reagents assuming a grand canonical ensemble and using the considerations of an electrophilic system using B3LYP/6-31G(d) and M06-2X/6-311 + G(d,p) methods. The DA reactions studied have the nucleophile (Cp) common; therefore, the increases of the polar character can be explained by the nature of the electrophilic carbons 
in the dienophiles and its CT, respectively; in this sense an analysis of CT using the $\Delta N_{\max 1}(k)$ is performed, and these $\Delta N_{\max 1}(k)$ values have a good statistical correlation $\left(R^{2}=\right.$ 0.9118 ) with the experimental rate constants, using reactivity models based on molecular recognition descriptors.

To study the quantum distortion using similarity descriptors the Et-TS of the $(\mathrm{Cp}+\mathrm{Et})$ in the reference reaction in order to study the electronic and structural effects on the TSs using the MQS field was used as molecular alignment pattern, taking into account that the similarity indexes are mathematically defined in the interval $(0,1]$ where 0 means complete (dis)similarity and 1 the self-similarity. The higher structural and electronic effects are presented in the TS-4CN with respect to TS-Et and are agreeing with the CT values and the experimental rate constants $\left(R^{2}=0.7127\right)$. In this sense, this study shows a good complementarity between quantum similarity and chemical reactivity in the DFT framework, generating similarity sequences and describing the polar character through CT and molecular polarization effects; in this sense new insights on the electronic reorganization associated with the DA reactions are shown, consistent with the experimental results.

Additionally, one of the most important fields in the quantum similarity is the measurement of similarity on reactivity properties that vary with the position change, taking into account the dependence of the molecular alignment in the (MQS) values. In this sense, the property to quantify the degree of similarity chosen in this study is the (CT) that allowed us to describe the chemical reactivity of these reactions in a systematic way and determining the similarity on the (CT) along the reactions and in terms of the polar character trend.

\section{Conflict of Interests}

The authors declare that there is no conflict of interests regarding the publication of this paper.

\section{Acknowledgments}

Alejandro Morales-Bayuelo expresses his thanks to the Universidad Nacional Andres Bello (UNAB) by a fellowship: CONICYT (63100003). Ricardo Vivas-Reyes is indebted to the Universidad de Cartagena (Cartagena de Indias, Colombia), for the continuous support to this research group.

\section{References}

[1] F. Fringuelli and A. Tatacchi, Diels-Alder Reactions: Selected Practical Methods, Wiley, New York, NY, USA, 2001.

[2] P. B. Karadakov, D. L. Cooper, and J. Gerratt, "Modern valencebond description of chemical reaction mechanisms: Diels-Alder reaction," Journal of the American Chemical Society, vol. 120, no. 16, pp. 3975-3981, 1998.

[3] H. Lischka, E. Ventura, and M. Dallows, "The Diels-Alder reaction of ethene and 1,3-butadiene: an extended multireference ab initio investigation," ChemPhysChem, vol. 5, no. 9, pp. 13651371, 2004.
[4] E. Kraka, A. Wu, and D. Cremer, "Mechanism of the diels-Alder reaction studied with the united raction valley approach: mechanistic differences between symmetry-allowed and symmetryforbidden reactions," Journal of Physical Chemistry A, vol. 107, no. 42, pp. 9008-9021, 2003.

[5] H. Isobe, Y. Takano, Y. Kitagawa et al., "Systematic comparisons between broken symmetry and symmetry-adapted approaches to transition states by chemical indices: a case study of the DielsAlder reactions," Journal of Physical Chemistry A, vol. 107, no. 5, pp. 682-694, 2003.

[6] O. Diels and K. Alder, "Synthesen in der hydroaromatischen Reihe," Justus Liebigs Annalen Der Chemie, vol. 460, no. 1, pp. 98-122, 1928.

[7] K. N. Houk, R. J. Loncharich, J. F. Blake, and W. L. Jorgensen, "Substituent effects and transition structures for Diels-Alder reactions of butadiene and cyclopentadiene with cyanoalkenes," Journal of the American Chemical Society, vol. 111, no. 26, pp. 9172-9176, 1989.

[8] K. C. Nicolaou, S. A. Snyder, T. Montagnon, and G. Vassilikogiannakis, "The Diels-Alder reaction in total synthesis," Angewandte Chemie: International Edition, vol. 41, no. 10, pp. 1668-1698, 2002.

[9] I. Fleming, Frontier Orbitals and Organic Chemical Reactions, John Wiley and Sons, New York, NY, USA, 1976.

[10] I. Fleming, Pericyclic Reaction, Oxford University Press, Oxford, UK, 1999.

[11] R. B. Woodward and R. Hoffmann, "The conservation of orbital symmetry," Angewandte Chemie: International Edition, vol. 8, no. 11, pp. 781-853, 1969.

[12] R. B. Woodward and R. Hoffmann, The Conservation of Orbital Symmetry, Academic Press, New York, NY, USA, 1970.

[13] R. Walsh and J. M. Wells, "The kinetics of reversible DielsAlder reactions in the gas phase-part II. Cyclopentadiene and ethylene," Journal of the Chemical Society, Perkin Transactions, vol. 2, pp. 52-55, 1976.

[14] J. Sauer, H. Wiest, and A. Mielert, "Eine studie der DielsAlder-reaktion-I. Die reaktivit $\mathrm{t}$ von dienophilen gegenüber cyclopentadien und 9.10-dimethyl-anthracen ", Chemische Berichte, vol. 97, pp. 3183-3207, 1964.

[15] L. Domingo, J. M. Aurell, P. Pérez, and R. Contreras, "Origin of the synchronicity on the transition structures of polar DielsAlder reactions. Are these reactions [4+2] processes?" Journal of Organic Chemistry, vol. 68, pp. 3884-3890, 2003.

[16] L. Domingo and J. Saéz, "Understanding the mechanism of polar Diels-Alder reactions," Organic \& Biomolecular Chemistry, vol. 7, pp. 3576-3583, 2009.

[17] L. Domingo, J. M. Aurell, P. Pérez, and R. Contreras, "Quantitative characterization of the local electrophilicity of organic molecules. Understanding the regioselectivity on Diels-Alder reactions," Journal of Physical Chemistry A, vol. 106, pp. 68716875, 2002.

[18] W. Yang, R. G. Parr, and R. Pucci, "Electron density, Kohn-Sham frontier orbitals, and Fukui functions," The Journal of Chemical Physics, vol. 81, no. 6, pp. 2862-2863, 1984.

[19] P. W. Ayers, W. T. Yang, and L. J. Bartolotti, "Fukui function," in Chemical Reactivity Theory: A Density Functional View, P. K. Chattaraj, Ed., pp. 255-267, CRC Press, Boca Raton, Fla, USA, 2009. 
[20] P. W. Ayers and M. Levy, "Perspective on: density functional approach to the frontier-electron theory of chemical reactivity," Theoretical Chemistry Accounts, vol. 103, no. 3-4, pp. 353-360, 2000.

[21] A. Szabo and N. S. Ostlund, Modern Quantum Chemistry, Dover Publishing, Mineola, NY, USA, 1996.

[22] C. J. Cramer, Essentials of Computational Chemistry, John Wiley and Sons, Chichester, UK, 2002.

[23] T. Sommerfeld, "Lorentz trial function for the hydrogen atom: a simple, elegant exercise," Journal of Chemical Education, vol. 88, no. 11, pp. 1521-1524, 2011.

[24] K. Fukui, "The role of frontier orbitals in chemical reactions (Nobel lecture)," Angewandte Chemie International, vol. 21, no. 11, pp. 801-809, 1982.

[25] K. Fukui, T. Yonezawa, and H. Shingu, "A molecular orbital theory of reactivity in aromatic hydrocarbons," The Journal of Chemical Physics, vol. 20, no. 4, pp. 722-725, 1952.

[26] M. Bernard, Organic Chemistry: Reactions and Mechanisms, Pearsons, Upper Saddle River, NJ, USA, 2004.

[27] H. Eyring, "The activated complex and the absolute rate of chemical reactions," Chemical Reviews, vol. 17, no. 1, pp. 65-77, 1935.

[28] K. J. Laidler and M. C. King, "The development of transitionstate theory," Journal of Physical Chemistry, vol. 87, no. 15, pp. 2657-2664, 1983.

[29] P. Geerlings, P. W. Ayers, A. Toro-Labbé, P. K. Chattaraj, and F. De Proft, "The Woodward-Hoffmann rules reinterpreted by conceptual density functional theory," Accounts of Chemical Research, vol. 45, no. 5, pp. 683-695, 2012.

[30] P. Hohenberg and W. Kohn, "Inhomogeneous electron gas," Physical Review, vol. 136, no. 3B, pp. B864-B871, 1964.

[31] D. H. Ess, G. O. Jones, and K. N. Houk, "Conceptual, qualitative, and quantitative theories of 1,3-dipolar and DielsAlder cycloadditions used in synthesis," Advanced Synthesis and Catalysis, vol. 348, pp. 2337-2361, 2006.

[32] E. Goldstein, B. Beno, and K. N. Houk, "Density functional theory prediction of the relative energies and isotope effects for the concerted and stepwise mechanisms of the Diels-Alder reaction of butadiene and ethylene," Journal of the American Chemical Society, vol. 118, no. 25, pp. 6036-6043, 1996.

[33] F. Bernardi, A. Bottini, M. A. Robb, M. J. Field, I. H. Hillier, and M. F. Guest, "Towards an accurate ab initio calculation of the transition state structures of the Diels-Alder reaction," Journal of the Chemical Society, Chemical Communications, vol. 7, no. 15, pp. 1051-1052, 1985.

[34] F. Bernardi, A. Bottoni, M. J. Field et al., "MC-SCF study of the Diels-Alder reaction between ethylene and butadiene," Journal of the American Chemical Society, vol. 110, no. 10, pp. 3050-3055, 1988.

[35] R. E. Townshend, G. Ramunni, G. Segal, W. J. Hehre, and L. Salem, "Organic transition states. V: the diels-alder reaction," Journal of American Chemical Society, vol. 98, no. 8, pp. 21902198, 1976.

[36] W. L. Jorgensen, D. Lim, and J. F. Blake, "Ab initio study of Diels-Alder reactions of cyclopentadiene with ethylene, isoprene, cyclopentadiene, acrylonitrile, and methyl vinyl ketone," Journal of the American Chemical Society, vol. 115, no. 7, pp. 2936-2942, 1993.
[37] S. Berski, J. Andrés, B. Silvi, and L. R. Domingo, “The joint use of catastrophe theory and electron localization function to characterize molecular mechanisms: a density functional study of the Diels-Alder reaction between ethylene and 1,3butadiene," Journal of Physical Chemistry A, vol. 107, no. 31, pp. 6014-6024, 2003.

[38] L. A. Burke and G. Leroy, "Corrigendum," Theoretica Chimica Acta, vol. 44, no. 2, pp. 219-221, 1977.

[39] L. A. Burke, G. Leroy, and M. Sana, "Theoretical study of the Diels-Alder reaction," Theoretica Chimica Acta, vol. 40, no. 4, pp. 313-321, 1975.

[40] M. Ortega, A. Oliva, J. M. Lluch, and J. Bertran, "The effect of the correlation energy on the mechanism of the Diels-Alder reaction," Chemical Physics Letters, vol. 102, no. 4, pp. 317-320, 1983.

[41] K. N. Houk, Y. T. Lin, and F. K. Brown, "Evidence for the concerted mechanism of the Diels-Alder reaction of butadiene with ethylene," Journal of the American Chemical Society, vol. 108, no. 3, pp. 554-556, 1986.

[42] F. K. Brown and K. N. Houk, "The STO-3G transition structure of the Diels-Alder reaction," Tetrahedron Letters, vol. 25, no. 41, pp. 4609-4612, 1984.

[43] M. J. S. Dewar, S. Olivella, and J. J. P. Stewart, "Mechanism of the Diels-Alder reaction: reactions of butadiene with ethylene and cyanoethylenes," Journal of the American Chemical Society, vol. 108, no. 19, pp. 5771-5779, 1986.

[44] K. N. Houk and L. L. Munchausen, "Ionization potentials, electron affinities, and reactivities of cyanoalkenes and related electron-deficient alkenes: a frontier molecular orbital treatment of cyanoalkene reactivities in cycloaddition, electrophilic, nucleophilic, and radical reactions," Journal of the American Chemical Society, vol. 98, no. 4, pp. 937-946, 1976.

[45] Y. Cao, S. Osune, Y. Liang, R. C. Haddon, and K. N. Houk, "Diels-alder reactions of graphene: computational predictions of products and sites of reaction," Journal of the American Chemical Society, vol. 135, no. 46, pp. 17643-17649, 2013.

[46] T. Karcher, W. Sicking, J. Sauer, and R. Sustmann, "Solvent effects on endo-exo selectivities in $(4+2)$ cycloadditions of cyanoethylenes," Tetrahedron Letters, vol. 33, no. 52, pp. 80278030,1992

[47] W. L. Jorgensen, D. Lim, and J. F. Blake, "Ab initio study of Diels-Alder reactions of cyclopentadiene with ethylene, isoprene, cyclopentadiene, acrylonitrile, and methyl vinyl ketone," Journal of the American Chemical Society, vol. 115, no. 7, pp. 2936-2942, 1993.

[48] B. S. Jursic, "Comparison of AM1 and density functional theory generated transition state structures and activation energies for cyanoalkenes addition to cyclopentadiene," Journal of Molecular Structure: THEOCHEM, vol. 358, pp. 139-143, 1995.

[49] V. Branchadell, "Density functional study of Diels-Alder reactions between cyclopentadiene and substituted derivatives of ethylene," International Journal of Quantum Chemistry, vol. 61, no. 3, pp. 381-388, 1997.

[50] G. O. Jones, V. A. Guner, and K. N. Houk, "Diels-Alder reactions of cyclopentadiene and 9,10-dimethylanthracene with cyanoalkenes: the performance of density functional theory and hartree-fock calculations for the prediction of substituent effects," Journal of Physical Chemistry A, vol. 110, no. 4, pp. 12161224, 2006. 
[51] R. Ponec, Topics in Current Chemistry, Springer, Berlin, Germany, 1995.

[52] R. Carbó-Dorca, "Mathematical aspects of the LCAO MO first order density function (5): centroid shifting of MO shape functions basis set, properties and applications," Journal of Mathematical Chemistry, vol. 51, no. 1, pp. 289-296, 2013.

[53] F. Fratev, O. E. Polansky, A. Mehlhorn, and V. Monev, "Application of distance and similarity measures. The comparison of molecular electronic structures in arbitrary electronic states," Journal of Molecular Structure, vol. 56, pp. 245-253, 1979.

[54] O. E. Polansky and G. Derflinger, “Zur Clar'schen Theorie Lokaler Benzoider Gebiete in Kondensierten Aromaten," International Journal of Quantum Chemistry, vol. 1, no. 4, pp. 33793401, 1967.

[55] P. E. Bowen-Jenkins, D. L. Cooper, and W. G. Richards, "Ab initio computation of molecular similarity," Journal of Physical Chemistry, vol. 89, no. 11, pp. 2195-2197, 1985.

[56] E. E. Hodgkin and W. G. Richards, "A semi-empirical method for calculating molecular similarity," Journal of the Chemical Society, Chemical Communications, vol. 17, pp. 1342-1344, 1986.

[57] R. Ponec and C. Czech, "Topological aspects of chemical reactivity. On the similarity of molecular structures," Chemical Communications, vol. 52, pp. 555-562, 1987.

[58] R. Ponec and M. Strnad, "Position invariant index for assessment of molecular similarity," Croatica Chemica Acta, vol. 66, pp. 1123-1127, 1993.

[59] D. L. Cooper and N. L. Allan, "A novel approach to molecular similarity," Journal of Computer-Aided Molecular Design, vol. 3, no. 3, pp. 253-259, 1989.

[60] D. L. Cooper and N. L. Allan, "Molecular dissimilarity: a momentum-space criterion," Journal of the American Chemical Society, vol. 114, no. 12, pp. 4773-4776, 1992.

[61] R. Carbó-Dorca and B. Calabuig, "Molecular quantum similarity measures and $\mathrm{N}$-dimensional representation of quantum objects. I. Theoretical foundations," International Journal of Quantum Chemistry, vol. 42, no. 6, pp. 1681-1693, 1992.

[62] J. Cioslowski and E. D. Fleischmann, "Assessing molecular similarity from results of ab initio electronic structure calculations," Journal of the American Chemical Society, vol. 113, no. 1, pp. 6467, 1991.

[63] Carbó-Dorca and R. Arnau M, "How similar is a molecule to another An electron density measure of similarity between two molecular structures," International Journal of Quantum Chemistry, vol. 17, no. 6, pp. 1185-1189, 1980.

[64] L. Amat and R. Carbó-Dorca, "Use of promolecular ASA density functions as a general algorithm to obtain starting MO in SCF calculations," International Journal of Quantum Chemistry, vol. 87, no. 2, pp. 59-67, 2002.

[65] X. Gironés and R. Carbó-Dorca, "Modelling toxicity using molecular quantum similarity measures," QSAR and Combinatorial Science, vol. 25, pp. 579-589, 2006.

[66] M. M. Deza and E. Deza, Encyclopedia of Distances, Springer, Berlin, Germany, 2009.

[67] S. K. Berberian, Introduction To Hilbert Space, Oxford University Press, New York, NY, USA, 1961.

[68] R. Carbó-Dorca and E. Besalú, "Centroid origin shift of quantum object sets and molecular point clouds description and element comparisons," Journal of Mathematical Chemistry, vol. 50, pp. 1161-1178, 2012.

[69] L. D. Mercado and R. Carbó-Dorca, "Quantum similarity and discrete representation of molecular sets," Journal of Mathematical Chemistry, vol. 49, no. 8, pp. 1558-1572, 2011.

[70] R. Carbó-Dorca and X. Gironés, "Foundation of quantum similarity measures and their relationship to QSPR: density function structure, approximations, and application examples," International Journal of Quantum Chemistry, vol. 101, no. 1, pp. 8-20, 2005.

[71] R. Carbó-Dorca, "Scaled Euclidian distances: a general dissimilarity index with a suitably defined geometrical foundation," Journal of Mathematical Chemistry, vol. 50, no. 4, pp. 734-740, 2012.

[72] P. Bultinck, X. Gironés, and R. Carbó-Dorca, "Molecular quantum similarity: theory and applications," in Reviews in Computational Chemistry, vol. 21, chapter 2, p. 127, 2005.

[73] R. Carbó-Dorca and E. Besalú, "Communications on quantum similarity (2): a geometric discussion on holographic electron density theorem and confined quantum similarity measures," Journal of Computational Chemistry, vol. 31, no. 13, pp. 24522462, 2010.

[74] R. Carbó-Dorca and L. D. Mercado, "Commentaries on quantum similarity (1): density gradient quantum similarity," Journal of Computational Chemistry, vol. 31, no. 11, pp. 2195-2212, 2010.

[75] R. Carbó-Dorca, E. Besalú, and L. D. Mercado, "Communications on quantum similarity-part 3: a geometric-quantum similarity molecular superposition algorithm," Journal of Computational Chemistry, vol. 324, pp. 582-599, 2011.

[76] M. Randić, "On characterization of molecular branching," Journal of the American Chemical Society, vol. 97, no. 23, pp. 6609-6615, 1975.

[77] R. Carbó-Dorca, "Scaled Euclidian distances: a general dissimilarity index with a suitably defined geometrical foundation," Journal of Mathematical Chemistry, vol. 50, no. 4, pp. 734-740, 2012.

[78] R. Carbó-Dorca, "Collective Euclidian distances and quantum similarity," Journal of Mathematical Chemistry, vol. 51, no. 1, pp. 338-353, 2013.

[79] P. W. Ayers, J. S. M. Anderson, and L. J. Bartolotti, "Perturbative perspectives on the chemical reaction prediction problem," International Journal of Quantum Chemistry, vol. 101, no. 5, pp. 520-534, 2005.

[80] J. L. Gázquez, "Perspectives on the density functional theory of chemical reactivity," Journal of the Mexican Chemical Society, vol. 52, pp. 3-10, 2008.

[81] R. G. Parr, L. V. Szentpály, and S. Liu, "Electrophilicity index," Journal of the American Chemical Society, vol. 121, no. 9, pp. 1922-1924, 1999.

[82] A. T. Maynard, M. Huang, W. G. Rice, and D. G. Covell, "Reactivity of the HIV-1 nucleocapsid protein p7 zinc finger domains from the perspective of density-functional theory," Proceedings of the National Academy of Sciences of the United States of America, vol. 95, no. 20, pp. 11578-11583, 1998.

[83] H. Chermette, "Chemical reactivity indexes in density functional theory," Journal of Computational Chemistry, vol. 20, no. 1, pp. 129-154, 1999. 
[84] S. Liu, "Conceptual density functional theory and some recent developments," Acta Physico-Chimica Sinica, vol. 25, pp. 590600, 2009.

[85] S. Berski, J. Andrés, B. Silvi, and L. R. Domingo, “The joint use of catastrophe theory and electron localization function to characterize molecular mechanisms. A density functional study of the Diels-Alder reaction between ethylene and 1,3butadiene," Journal of Physical Chemistry A, vol. 107, no. 31, pp. 6014-6024, 2003.

[86] A. Morales-Bayuelo, "Understanding the electronic reorganization in the thermal isomerization reaction of trans-3,4dimethylcyclobutene. Origins of outward Pseudodiradical 2n + $2 \pi$ torquoselectivity," International Journal of Quantum Chemistry, vol. 113, no. 10, pp. 1534-1543, 2013.

[87] A. Morales-Bayuelo and R. Vivas-Reyes, "Theoretical model for the polarization molecular and Hückel treatment of PhosphoCyclopentadiene in an external electric field: Hirschfeld study," Journal of Mathematical Chemistry, vol. 51, no. 7, pp. 1835-1852, 2013.

[88] A. Morales-Bayuelo and R. Vivas-Reyes, "Topological model to quantify the global reactivity indexes as local in DielsAlder reactions, using density function theory (DFT) and local quantum similarity (LQS)," Journal of Mathematical Chemistry, vol. 51, no. 1, pp. 125-143, 2013.

[89] A. Morales-Bayuelo, V. Valdiris, and R. Vivas-Reyes, "Mathematical analysis of a series of 4-acetylamino-2-(3,5-dimethylpyrazollyl)-6-pyridylpyrimidines: a simple way to relate quantum similarity to local chemical reactivity using the Gaussian orbitals localized theory," Journal of Theoretical Chemistry, vol. 2014, Article ID 624891, 13 pages, 2014.

[90] A. Morales-Bayuelo and R. Vivas-Reyes, “Topological model to quantify the global reactivity indexes as local in DielsAlder reactions, using density function theory (DFT) and local quantum similarity (LQS)," Journal of Mathematical Chemistry, vol. 51, no. 1, pp. 125-143, 2013.

[91] A. Morales-Bayuelo, R. Baldiris, J. Torres, J. E. Torres, and R. Vivas-Reyes, "Theoretical study of the chemical reactivity and molecular quantum similarity in a series of derivatives of 2adamantyl-thiazolidine-4-one using density functional theory and the topo-geometrical superposition approach," International Journal of Quantum Chemistry, vol. 112, no. 14, pp. 26812687, 2012.

[92] P. Geerlings, F. De Proft, and W. Langenaeker, "Conceptual density functional theory," Chemical Reviews, vol. 103, no. 5, pp. 1793-1873, 2003.

[93] H. Chermette, "Chemical reactivity indexes in density functional theory," Journal of Computational Chemistry, vol. 20, no. 1, pp. 129-154, 1999.

[94] P. W. Ayers and R. G. Parr, "Variational principles for describing chemical reactions: the Fukui function and chemical hardness revisited," Journal of the American Chemical Society, vol. 122, no. 9, pp. 2010-2018, 2000.

[95] P. Geerlings and F. De Proft, "Conceptual and computational dft as a chemist's tool," in Recent Advances in Computational Chemistry, vol. 1, pp. 137-167, 2002.

[96] P. W. Ayers, S. B. Liu, and T. L. Li, "Stability conditions for density functional reactivity theory: an interpretation of the total local hardness," Physical Chemistry Chemical Physics, vol. 13, pp. 4427-4433, 2011.
[97] P. Geerlings and F. de Proft, "Chemical reactivity as described by quantum chemical methods," International Journal of Molecular Sciences, vol. 3, pp. 276-309, 2002.

[98] R. F. Nalewajski and R. G. Parr, "Information theory, atoms in molecules, and molecular similarity," Proceedings of the National Academy of Sciences, vol. 97, pp. 8879-8882, 2000.

[99] P. Bultinck and R. Carbó-Dorca, "Molecular quantum similarity using conceptual DFT descriptors," Journal of Chemical Sciences, vol. 117, pp. 425-435, 2005.

[100] R. Vivas-Reyes, A. Arias, J. Vandenbussche, C. V. Alsenoy, and P. Bultinck, "Quantum similarity of isosteres coordinate versus momentum space and influence of alignment," Journal of Molecular Structure: THEOCHEM, vol. 943, no. 1-3, pp. 183188, 2010.

[101] R. Carbó-Dorca, Molecular Similarity and Reactivity: From Quantum Chemical to Phenomenological Approaches, Kluwer Academic Publishers, 1995.

[102] P. Bultinck, S. V. Damme, and R. Carbó-Dorca, Chemical Reactivity Theory: A Density Functional View, CRC Press, 2009.

[103] J. Mestres, M. Solà, M. Besalú, M. Duran, and R. Carbó-Dorca, "Electron density approximations for the fast evaluation of quantum molecular similarity measures," in A Molecular Similarity and Reactivity: From Quantum Chemical to Phenomenological Approaches, pp. 77-85, Kluwer Academic Publishers, 1995.

[104] R. G. Pearson, Chemical Hardness, Wiley-VCH, Weinheim, Germany, 1997.

[105] W. T. Yang and R. G. Parr, "Hardness, softness, and the fukui function in the electronic theory of metals and catalysis," Proceedings of the National Academy of Sciences of the United States of America, vol. 82, no. 20, pp. 6723-6726, 1985.

[106] M. T. Chandra and A. K. Nguyen, "Fukui function and local softness as reactivity descriptors," in Chemical Reactivity Theory: A Density-Functional View, P. K. Chattaraj, Ed., p. 163, Taylor and Francis, New York, NY, USA, 2008.

[107] R. G. Parr, L. V. Szentpály, and S. Liu, "Electrophilicity index," Journal of the American Chemical Society, vol. 121, no. 9, pp. 1922-1924, 1999.

[108] R. G. Parr and W. Yang, "Density functional approach to the frontier-electron theory of chemical reactivity," Journal of the American Chemical Society, vol. 106, no. 14, pp. 4049-4050, 1984.

[109] K. Fukui, "Role of frontier orbitals in chemical reactions," Science, vol. 218, no. 4574, pp. 747-754, 1982.

[110] J. Tomasi and M. Persico, "Molecular interactions in solution: an overview of methods based on continuous distributions of the solvent," Chemical Reviews, vol. 94, no. 7, pp. 2027-2094, 1994.

[111] E. Cances, B. Mennucci, and J. Tomasi, "A new integral equation formalism for the polarizable continuum model: theoretical background and applications to isotropic and anisotropic dielectrics," Journal of Chemical Physics, vol. 107, article 3032, 1997.

[112] A. D. McLean and G. S. Chandler, "Contracted Gaussian basis sets for molecular calculations. I. Second row atoms, $Z=11-18$," The Journal of Chemical Physics, vol. 72, no. 10, pp. 5639-5648, 1980.

[113] R. Carbó-Dorca and E. Besalú, "EMP as a similarity measure: a geometric point of view," Journal of Mathematical Chemistry, vol. 51, no. 1, pp. 382-389, 2013. 
[114] E. E. Hodgkin and W. G. Richards, "Molecular Similarity," Chemische Berichte, vol. 24, p. 1141, 1988.

[115] R. Carbó-Dorca, "Scaled Euclidian distances: a general dissimilarity index with a suitably defined geometrical foundation," Journal of Mathematical Chemistry, vol. 50, no. 4, pp. 734-740, 2012.

[116] A. Morales-Bayuelo, H. Ayazo, and R. Vivas-Reyes, "Threedimensional quantitative structure-activity relationship CoMSIA/CoMFA and LeapFrog studies on novel series of bicyclo [4.1.0] heptanes derivatives as melanin-concentrating hormone receptor R1 antagonists," European Journal of Medicinal Chemistry, vol. 45, no. 10, pp. 4509-4522, 2010.

[117] X. Gironés and R. Carbó-Dorca, “TGSA-Flex: extending the capabilities of the Topo-Geometrical superposition algorithm to handle flexible molecules," Journal of Computational Chemistry, vol. 25, no. 2, pp. 153-159, 2004.

[118] L. Chen, "Substructure and maximal common substructure searching," in Computational Medicinal Chemistry For Drug Discovery, P. Bultinck, H. De Winter, W. Langenaeker, and J. P. Tollenaere, Eds., p. 483, Marcel Dekker, New York, NY, USA, 2003.

[119] X. Girones, D. Robert, and R. Carbó-Dorca, "TGSA: a molecular superposition program based on topo-geometrical considerations," Journal of Computational Chemistry, vol. 22, no. 2, pp. 255-263, 2001.

[120] H. B. Schlegel, "Optimization of equilibrium geometries and transition structures," Journal of Computational Chemistry, vol. 3, pp. 214-218, 1982.

[121] H. B. Schlegel, "Geometry optimization on potential energy surface," in Modern Electronic Structure Theory, D. R. Yarkony, Ed., World Scientific Publishing, Singapore, 1994.

[122] M. J. Frisch, G. W. Trucks, H. B. Schlegel et al., GAUSSIAN 09, Revision C. 01, Gaussian, Wallingford, Conn, USA, 2010.

[123] A. D. Becke, "Density-functional thermochemistry. III. The role of exact exchange," The Journal of Chemical Physics, vol. 98, no. 7, pp. 5648-5652, 1993.

[124] C. Lee, W. Yang, and R. G. Parr, "Development of the ColleSalvetti correlation-energy formula into a functional of the electron density," Physical Review B: Condensed Matter, vol. 37, pp. 785-789, 1998.

[125] P. J. Stephens, F. J. Delvin, C. F. Chablowski, and M. J. J. Firsch, "Ab initio calculation of vibrational absorption and circular dichroism spectra using density functional force fields," Physical Chemistry, vol. 98, no. 45, pp. 11623-11627, 1994.

[126] J. A. Pople, P. V. Schleyer, W. J. Hehre, and L. Radom, AB INITIO molecular orbital theory, 1986.

[127] S. C. Pellegrinet, M. A. Silva, and J. M. Goodman, "Theoretical evaluation of the origin of the regio- and stereoselectivity in the Diels-Alder reactions of dialkylvinylboranes: studies on the reactions of vinylborane, dimethylvinylborane, and vinyl9-BBN with trans-piperylene and isoprene," Journal of the American Chemical Society, vol. 123, no. 36, pp. 8832-8837, 2001.

[128] T. C. Dinadayalane, R. Vijaya, A. Smitha, and G. N. Sastry, "Diels-Alder reactivity of butadiene and cyclic five-membered dienes $((\mathrm{CH}) 4 \mathrm{X}, \mathrm{X}=\mathrm{CH} 2, \mathrm{SiH} 2, \mathrm{O}, \mathrm{NH}, \mathrm{PH}$, and $\mathrm{S})$ with ethylene: a benchmark study," Journal of Physical Chemistry A, vol. 106, no. 8, pp. 1627-1633, 2002.
[129] R. Jasiński, Koifman, and A. Barański, “A B3LYP/6-31G(d) study of Diels-Alder reactions between cyclopentadiene and (E)-2arylnitroethenes," Central European Journal of Chemistry, vol. 9, no. 6, pp. 1008-1018, 2011.

[130] B. M. El Ali, "AJSE Relaunched in cooperation with Springer," Arabian Journal for Science and Engineering, vol. 36, no. 1, p. 1, 2011.

[131] M. Kwiatkowska, R. Jasinski, M. Mikulska, and A. Baranski, "Secondary alpha-deuterium kinetic isotope effects in $[2+4]$ cycloaddition of (E)-2-phenylnitroethene to cyclopentadiene," Monatshefte Für Chemie, vol. 141, no. 5, pp. 545-548, 2010.

[132] R. Jasinski and A. Baranski, "Molecular mechanism of DielsAlder reaction between (E)-3, 3, 3-trichloro-1-nitropropene and cyclopentadiene: B3LYP/6-31G(d) computational study," Turkish Journal of Chemistry, vol. 37, pp. 848-852, 2013.

[133] Y. Zhao and D. G. Truhlar, “The M06 suite of density functionals for main group thermochemistry, thermochemical kinetics, noncovalent interactions, excited states, and transition elements: two new functionals and systematic testing of four M06-class functionals and 12 other functionals," Theoretical Chemistry Accounts, vol. 120, no. 1-3, pp. 215-241, 2008.

[134] C. González and H. B. Schlegel, "Reaction path following in mass-weighted internal coordinates," Journal of Physical Chemistry, vol. 94, no. 14, pp. 5523-5527, 1990.

[135] C. González and H. B. Schlegel, "Improved algorithms for reaction path following: higher-order implicit algorithms," Journal of Chemical Physics, vol. 95, pp. 5853-5860, 1991.

[136] P. Geerlings, R. Vivas-Reyes, F. De Proft, M. Biesemans, and R. Willem, "DFT based reactivity descriptors and their application to the study of organotin compounds," in Metal-Ligand Interactions, vol. 116 of NATO Science Series, pp. 461-495, 2003.

[137] P. Geerlings, R. Vivas-Reyes, F. de Proft, M. Biesemans, and R. Willem, "DFT-based reactivity descriptors and their application to the study of organotin compounds," Cheminform, vol. 35, no. 49, 2004.

[138] P. W. Ayers and R. G. Parr, "Variational principles for describing chemical reactions: the Fukui function and chemical hardness revisited," Journal of the American Chemical Society, vol. 122, no. 9, pp. 2010-2018, 2000.

[139] P. Bultinck, C. Van Alsenoy, P. W. Ayers, and R. Carbó-Dorca, "Critical analysis and extension of the Hirshfeld atoms in molecules," Journal of Chemical Physics, vol. 126, no. 14, Article ID 144111, 2007.

[140] P. K. Chattaraj and D. R. Roy, "Update 1 of: electrophilicity index," Chemical Reviews, vol. 107, no. 9, pp. PR46-PR74, 2007.

[141] M. J. Frisch, G. W. Trucks, H. B. Schlegel et al., GAUSSIAN 09, Revision C. 01, Gaussian, Wallingford, Conn, USA, 2010.

[142] D. H. Ess and K. N. Houk, "Distortion/interaction energy control of 1,3-dipolar cycloaddition reactivity," Journal of the American Chemical Society, vol. 129, no. 35, pp. 10646-10647, 2007.

[143] D. H. Ess and K. N. Houk, "Theory of 1,3-dipolar cycloadditions: distortion/interaction and frontier molecular orbital models," Journal of the American Chemical Society, vol. 130, no. 31, pp. 10187-10198, 2008.

[144] A. M. Sarotti, "Unraveling polar Diels-Alder reactions with conceptual DFT analysis and the distortion/interaction model," Organic and Biomolecular Chemistry, vol. 12, pp. 187-199, 2014. 
[145] H. Jiao and P. von Ragué Schleyer, "Aromaticity of pericyclic reaction transition structures: magnetic evidence," Journal of Physical Organic Chemistry, vol. 11, no. 8-9, pp. 655-662, 1998.

[146] F. Feixas, E. Matito, J. Poater, and M. Solà, “On the performance of some aromaticity indices: a critical assessment using a test set," Journal of Computational Chemistry, vol. 29, no. 10, pp. 1543-1554, 2008.

[147] E. Matito, J. Poater, M. Duran, and M. Solà, "An analysis of the changes in aromaticity and planarity along the reaction path of the simplest Diels-Alder reaction. Exploring the validity of different indicators of aromaticity," Journal of Molecular Structure: THEOCHEM, vol. 727, no. 1-3, pp. 165-171, 2005.

[148] G. Boon, W. Langenaeker, F. De Proft, H. De Winter, J. P. Tollenaere, and P. Geerlings, "Systematic study of the quality of various quantum similarity descriptors. Use of the autocorrelation function and principal component analysis," Journal of Physical Chemistry A, vol. 105, no. 38, pp. 8805-8814, 2001.

[149] P. Seneta and F. Aparicio, "Density functional theory fragment descriptors to quantify the reactivity of a molecular family: application to amino acids," Journal of Chemical Physics, vol. 126, Article ID 145105, 2007.

[150] E. M. Burgess and C. L. Liotta, "Principle of orbital distortion," Journal of Organic Chemistry, vol. 46, no. 8, pp. 1703-1708, 1981.

[151] K. N. Houk, M. N. Paddon-Row, N. G. Rondan et al., “Theory and modeling of stereoselective organic reactions," Science, vol. 231, no. 4742, pp. 1108-1117, 1986.

[152] D. H. Rouvray, "Definition and role of similarity concepts in the chemical and physical sciences," Journal of chemical information and computer science, vol. 32, pp. 580-586, 1992.

[153] D. H. Rouvray, "Similarity studies. 1. The necessity for analogies in the development of science," Journal of Chemical Information and Computer Sciences, vol. 34, no. 2, pp. 446-452, 1994.

[154] E. C. Kirby and D. H. Rouvray, "Sixth international conference on mathematical chemistry," Journal of Chemical Information and Computer Sciences, vol. 36, no. 3, pp. 345-346, 19961996.

[155] S. R. Heller, "Similarity in organic chemistry: a summary of the Beilstein Institute Conference," Journal of Chemical Information and Computer Sciences, vol. 32, pp. 578-579, 1992. 

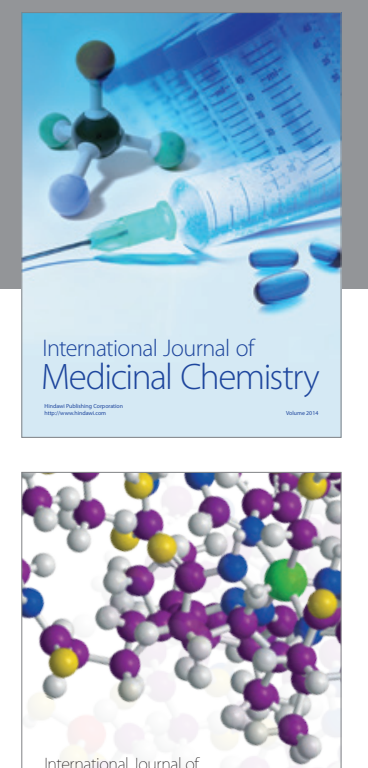

\section{Carbohydrate} Chemistry

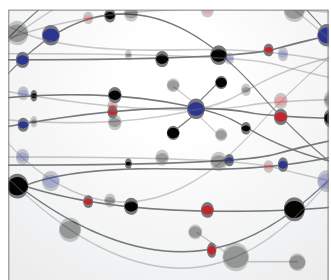

The Scientific World Journal
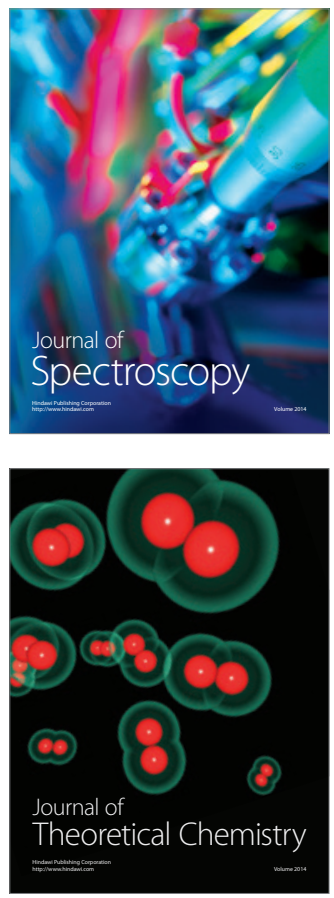
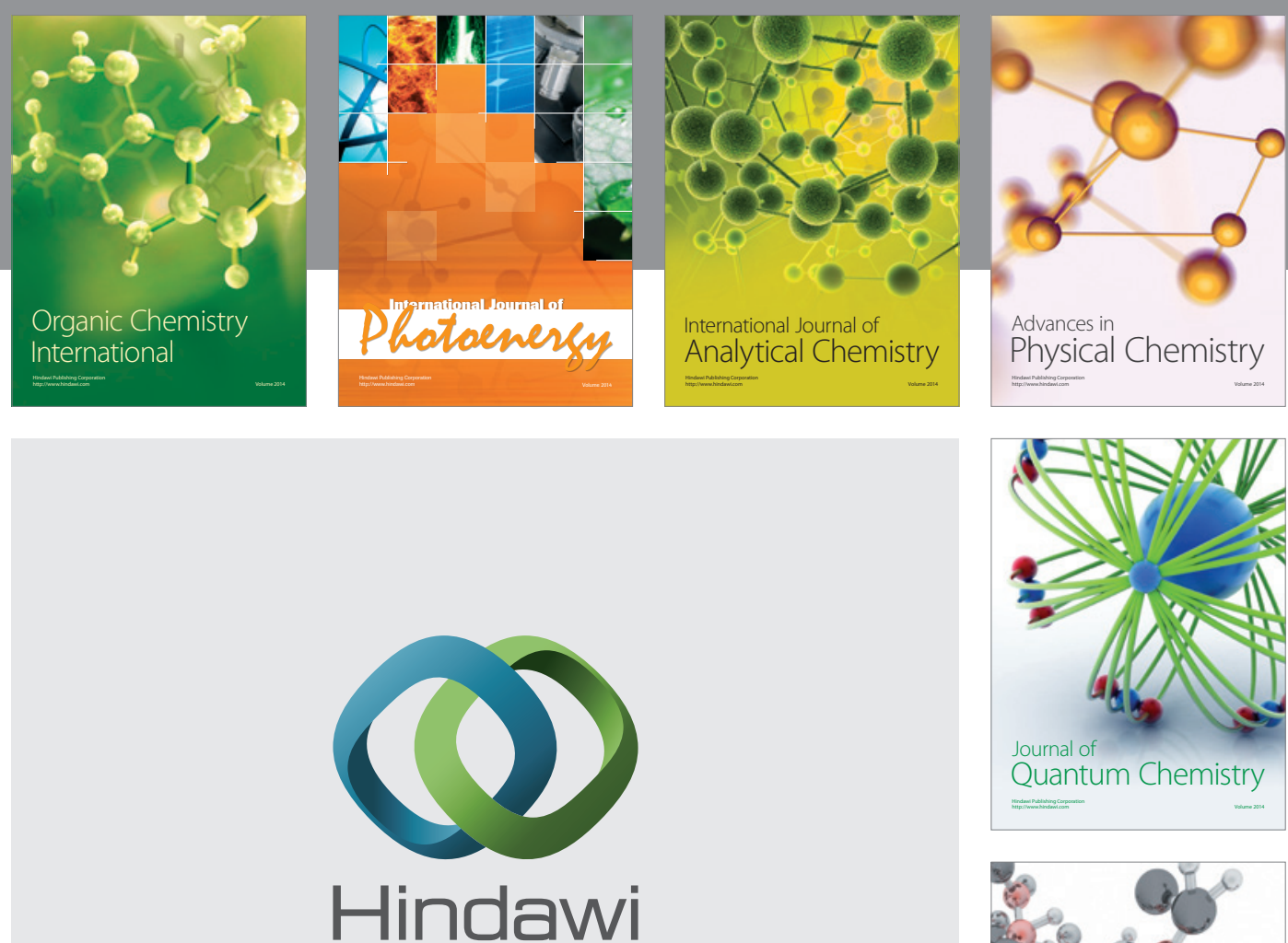

Submit your manuscripts at

http://www.hindawi.com

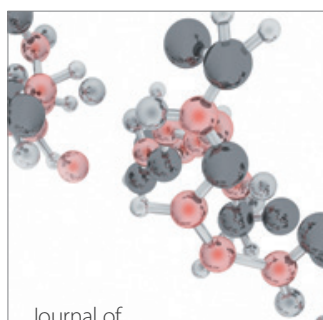

Analytical Methods

in Chemistry

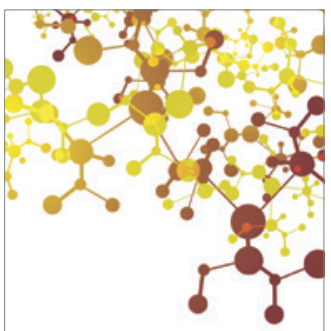

Journal of

Applied Chemistry

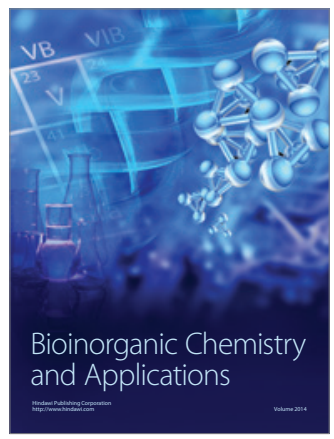

Inorganic Chemistry
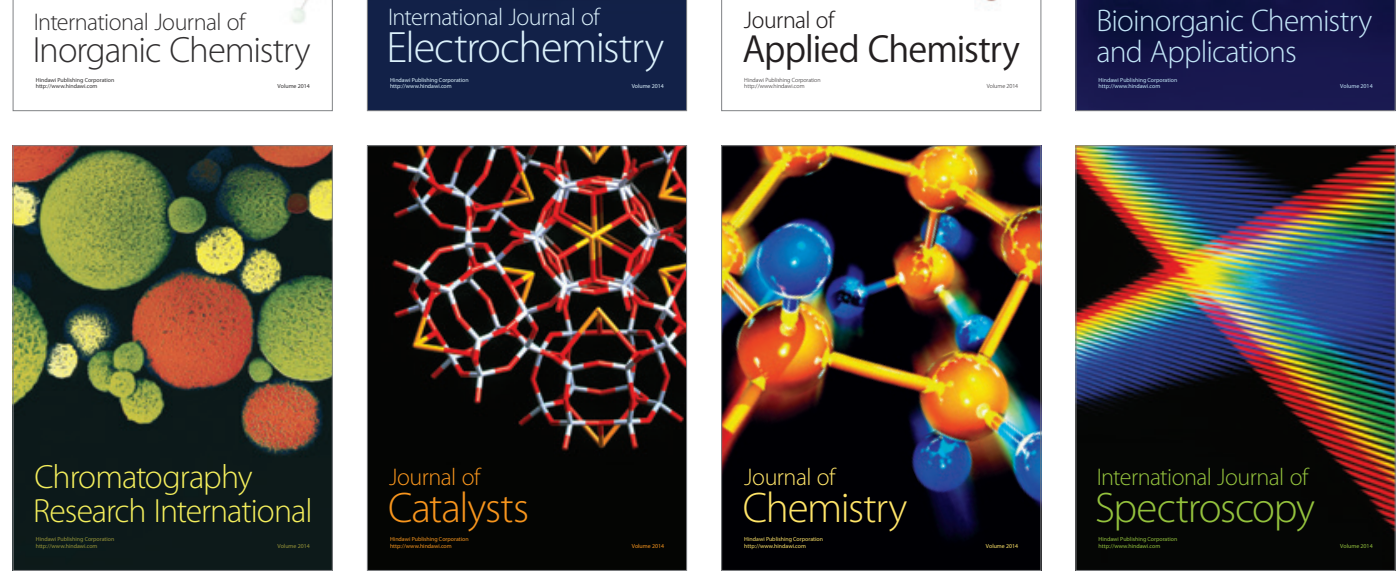